cussion had been given, for, in consequence of the vague headings on the opposite pages, it is often a matter of some little difficulty to discover to which particular bird the author is referring. Throughout his volume Mr. Selous is fond of interpolating phrases or quotations in foreign languages, inclusive of French, German, Latin, and Greek. Whether such a practice is altogether desirable may be a matter of opinion, but there will be only one opinion as to the desirability of quoting correctly, which is far from

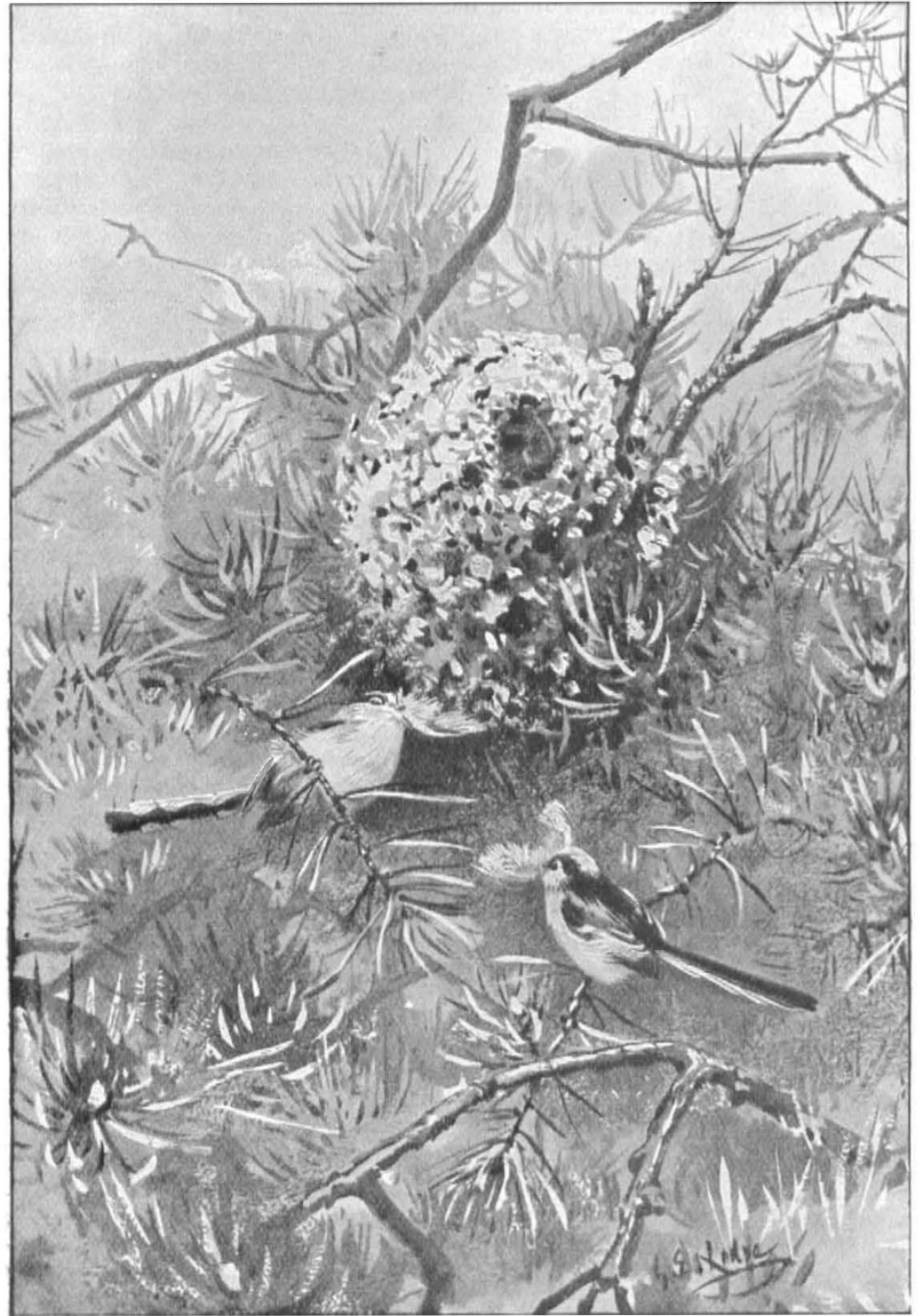

FIG. ז.-Long-tailed Tits and the Nest. From E. Selous's " B.rd Life Glimpses.' day.

to be delivered at Johannesburg on Wednesday, August 30, will appear in NATURE of the following

From a Reuter message we learn that on the conclusion of the address, the Governor, Sir Walter HelyHutchinson, in proposing a vote of thanks, bade the association heartily welcome on behalf of Cape Colony. The occasion was one, he said, of no ordinary importance, whether in the history of the development of scientific inquiry or in the history of the relations of the United Kingdom with the British dominions beyond the seas. He hoped it would be found that a great and important step had been taken in drawing closer together the bonds of the brotherhood of science, and, it might be, through the brotherhood of science, in promoting and developing brotherly feeling between His Majesty's subjects in South Africa and the Motherland.

Sir David Gill, K.C.B., chairman of the central organising committee at Cape Town, seconded the motion; and a brief reply by Prof. Darwin brought the proceedings to a close.

The addresses of all the presidents of sections were to be delivered yesterday on the assembling of the sections at Cape Town. The sections are also to meet for the reading and discussion of reports and papers to-day and tomorrow, and they will reassemble on Tuesday, August 29, at Johannesburg, where the concluding meeting will be held on September I, and the work of the sections will terminate.

Inaugural Address by Prof. G. H. DARWIN, M.A., LL.D., PH.D., F.R.S. President of the Association.

PART I.

BARTHOLOMEU Diaz, the discoverer 'of the Cape of Storms, spent sixteen months on his voyage, and the little flotilla of Vasco da Gama, sailing from Lisbon on July 8 , 1497, only reached the Cape in the middle of November. These bold men, sailing in their puny fishing smacks to unknown lands, met the perils of the sea and the attacks of savages with equal courage. How great was the danger of such a voyage may be gathered from the fact that less than half the men who sailed with da Gama lived to return to Lisbon. Four hundred and eight years have passed since that voyage, and a ship of 13,000 tons has just brought us here, in safety and luxury, in but little more than a fortnight.

How striking are the contrasts presented by these events! On the one hand com-

being the case when a well-known line from the second book of the Eneid is introduced on p. Iog.

R. L.

\section{THE SOUTH AFRICAN MEETING OF THE BRITISH ASSOCIATION.}

THE seventy-fifth meeting of the British Association was inaugurated at Cape Town on Tuesday, when the president, Prof. G. H. Darwin, F.R.S., delivered the first portion of his address to a large gathering in the new City Hall. This part is reprinted below, and the remainder of the address, NO. I 868 , vOL. 72$]$ pare the courage, the endurance, and the persistence of the early navigators with the little that has been demanded of us; on the other hand consider how much man's power over the forces of nature has been augmented during the past four centuries. The capacity for heroism is probably undiminished, but certainly the occasions are now rarer when it is demanded of us. If we are heroes, at least but few of us ever find it out, and, when we read stories of ancient feats of courage, it is hard to prevent an uneasy thought that, notwithstanding our boasted mechanical inventions, we are perhaps degenerate descendants of our great predecessors $\mathrm{s}$

Yet the thought that to-day is less romantic and less heroic than yesterday has its consolation, for it means 
that the lot of man is easier than it was. Mankind, indeed, may be justly proud that this improvement has been due to the successive efforts of each generation to add to the heritage of knowledge handed down to it by its predecessors, whereby we have been born to the accumulated endowment of centuries of genius and labour.

I am told that in the United States the phrase "I want to know" has lost the simple meaning implied by the words, and has become a mere exclamation of surprise. Such a conventional expression could hardly have gained currency except amongst a people who aspire to knowledge. The dominance of the European race in America, Australasia, and South Africa has no doubt arisen from many causes, but amongst these perhaps the chief one is that not only do "we want to know," but also that we are determined to find out. And now within the last quarter of a century we have welcomed into the ranks of those who "want to know" an oriental race, which has already proved itself strong in the peaceful arts of knowledge.

I take it, then, that you have invited us because you want to know what is worth knowing; and we are here because we want to know you, to learn what you have to tell us, and to see that South Africa of which we have heard so much.

The hospitality which you are offering us is so lavish, and the journeys which you have organised are so extensive, that the cynical observer might be tempted to describe our meeting as the largest picnic on record. Although we intend to enjoy our picnic with all our kearts, yet 1 should like to tell the cynic, if he is here, that perhaps the most important object of these conferences is the opportunity they afford for personal intercourse between men of like minds who live at the remotest rorners of the earth.

We shall pass through your land with the speed and the voracity of a flight of locusts; but, unlike the locust, we shall, I hope, leave behind us permanent fertilisation in the form of stimulated scientific and educational activity. And this result will ensue whether or not we who have come from Europe are able worthily to sustain the lofty part of prophets of science. We shall try our best to play to your satisfaction on the great stage upon which you call on us to act, and if when we are gone you shall, amongst yourselves, pronounce the performance a poor one, yet the fact will remain, that this meeting has embodied in a material form the desire that the progress of this great continent shall not be merely material; and such an aspiration secures its own fulfilment. However small may be the tangible results of our meeting, we shall always be proud to have been associated with you in your efforts for the advancement of science.

We do not know whether the last hundred years will be regarded for ever as the saeculum mirabile of discovery, or whether it is but the prelude to yet more marvellous centuries. To us living men, who scarcely pass a year of our lives without witnessing some new marvel of discovery or invention, the rate at which the development of knowledge proceeds is truly astonishing; but from a wider point of view the scale of time is relatively unimportant, for the universe is leisurely in its procedure Whether the changes which we witness be fast or slow, they form a part of a long sequence of events which begin in some past of immeasurable remoteness and tend to some end which we cannot foresee. It must always be profoundly interesting to the mind of man to trace successive cause and effect in the chain of events which make up the history of the earth and all that lives on it, and to speculate on the origin and future fate of animals, and of planets, suns, and stars. I shall try, then, to set forth in my address some of the attempts which have been made to formulate evolutionary speculation. This choice of a subject has, moreover, been almost forced on me by the scope of my own scientific work, and it is, I think, justified by the name which I bear. It will be my fault and your misfortune if I fail to convey to you some part of the interest which is naturally inherent in such researches.

The man who propounds a theory of evolution is attempting to reconstruct the history of the past by means of the circumstantial evidence afforded by the present.

No. I 868 , vOL. 72$]$
The historian of man, on the other hand, has the advantage over the evolutionist in that he has the written records of the past on which to rely. The discrimination of the truth from amongst discordant records is frequently a work demanding the highest qualities of judgment; yet when this end is attained it remains for the historian to convert the arid skeleton of facts into a living whole by clothing it with the flesh of human motives and impulses. For this part of his task he needs much of that power of entering into the spirit of other men's lives which goes to the making of a poet. Thus the historian should possess not only the patience of the man of science in the analysis of facts, but also the imagination of the poet to grasp what the facts have meant. Such a combination is rarely to be found in equal perfection on both sides, and it would not be hard to analyse the works of great historians so.as to see which quality was predominant in each of them.

The evolutionist is spared the surpassing difficulty of the human element, yet he also needs imagination, although of a different wharacter from that of the historian. In its lowest form his imagination is that of the detective who reconstructs the story of a crime; in its highest. it demands the power of breaking loose from all the trammels of convention and education, and of imagining something which has never occurred to the mind of man before. In every case the evolutionist must form a theory for the facts before him, and the great theorist is only to be distinguished from the fantastic fool by the sobriety of his judgment-a distinction, however, sufficient to make one rare and the other only too common.

The test of a scientific theory lies in the number of facts which it groups into a connected whole; it ought besides to be fruitful in pointing the way to the discovery and coordination of new and previously unsuspected facts. Thus a good theory is in effect a cyclopædia of knowledge, susceptible of indefinite- extension by the addition of supplementary volumes.

Hardly any theory is all true, and many are not alt false. A theory may be essentially at fault and yet point the way to truth, and so justify its temporary existence. We should not, therefore, totally reject one or other of two rival theories on the ground that they seem, with our present knowledge, mutually inconsistent, for it is likely that both may contain important elements of truth. The theories of which I shall have to speak hereafter may often appear discordant with one another according to our present lights. Yet we must not scruple to pursue the several divergent lines of thought to their logical conclusions, relying on future discovery to eliminate the false and to reconcile together the truths which form part of each of them.

In the mouths of the unscientific evolution is often spoken. of as almost synonymous with the evolution of the various species of animals on the earth, and this again is sometimes thought to be practically the same thing as the theory of natural selection. Of course those who are conversant with the history of scientific ideas are aware that a belief in the gradual and orderly transformation of nature, both animate and inanimate, is of great antiquity.

We may liken the facts on which theories of evolution are based to a confused heap of beads, from which a keensighted searcher after truth picks out and strings together a few which happen to catch his eye, as possessing certain resemblances. Until recently, theories of evolution in both realms of nature were partial and discontinuous, and the chains of facts were correspondingly short and disconnected. At length the theory of natural selection, by formulating the cause of the divergence of forms in the organic world from the parental stock, furnished the naturalist with a clue by which he examined the disordered mass of facts before him, and he was thus enabled to go far in deducing order where chaos had ruled before; but the problem of reducing the heap to perfect order will probably baffle the ingenuity of the investigator for ever.

So illuminating has been this new idea that, as the whole of nature has gradually been re-examined by its aid, thousands of new facts have been brought to light, and have been strung in due order on the necklace of knowledge. Indeed, the transformation resulting from the new 
point of view has been so far-reaching as almost to justify the misapprehension of the unscientific as to the date when the doctrines of evolution first originated in the mind of man.

It is not my object, nor indeed am I competent, to examine the extent to which the theory of natural selection has needed modification since it was first formulated by my father and Wallace. But I am surely justified in maintaining that the general principle holds its place firmly as a permanent acquisition to modes of thought.

Evolutionary doctrines concerning inanimate nature, although of much older date than those which concern life, have been profoundly affected by the great impulse of which I have spoken. It has thus come about that the origin and history of the chemical elements and of stellar systems now occupy a far larger space in the scientific mind than was formerly the case. The subject which I shall discuss to-night is the extent to which ideas, parallel to those which have done so much towards elucidating the problems of life, hold good also in the world of matter; and I believe that it will be possible to show that in this respect there exists a resemblance between the two realms of nature, which is not merely fanciful. It is proper to add that so long ago as 1873 Baron Karl du Prel discussed the same subject from a similar point of view, in a book entitled "The Struggle for Life in the Heavens." 1

Although inanimate matter moves under the action of forces which are incomparably simpler than those governing living beings, yet the problems of the physicist and the astronomer are scarcely less complex than those which present themselves to the biologist. The mystery of life remains as impenetrable as ever, and in his evolutionary speculations the biologist does not attempt to explain life itself, but, adopting as his unit the animal as a whole, discusses its relationships to other animals and to the surrounding conditions. The physicist, on the other hand, is irresistibly impelled to form theories as to the intimate constitution of the ultimate parts of matter, and he desires further to piece together the past histories and the future fates of planets, stars, and nebulæ. If then the speculations of the physicist seem in some respects less advanced than those of the biologist, it is chiefly because he is more ambitious in his aims. Physicists and astronomers have not yet found their Johannesburg or Kimberley; but although we are still mere prospectors, I am proposing to show you some of the dust and diamonds which we have already extracted from our surface mines.

The fundamental idea in the theory of natural selection is the persistence of those types of life which are adapted to their surrounding conditions, and the elimination by extermination of ill-adapted types. The struggle for life amongst forms possessing a greater or less degree of adaptation to slowly varying conditions is held to explain the gradual transmutation of species. Although a different phraseology is used when we speak of the physical world yet the idea is essentially the same.

The point of view from which I wish you to consider the phenomena of the world of matter may be best explained if, in the first instance, I refer to political institutions, because we all understand, or fancy we understand, something of politics, whilst the problems of physics are commonly far less familiar to us. This illustration will have a further advantage in that it will not be a mere parable, but will involve the fundamental conception of the nature of evolution.

The complex interactions of man with man in a community are usually described by such comprehensive terms as the State, the Commonwealth, or the Government. Various States differ widely in their constitution and in the degree of the complexity of their organisation, and we classify them by various general terms, such as autocracy, aristocracy, or democracy, which express somewhat loosely their leading characteristics. But, for the purpose of showing the analogy with physies, we need terms of wider import than those habitually used in politics. All forms of the State imply inter-relationship in the actions of men, and action implies movement. Thus the State may be described as a configuration or arrangement of a community of men; or we may say that it implies a 1 "Der Kampf um's Dasein am Himmel." Zweite Auflage. (Berlin:
Denicke, 8 876.)

NO. I 868 , vOL. 72$]$ definite mode of motion of man-that is to say, an organised scheme of action of man on man. Political history gives an account of the gradual changes in such configurations or modes of motion of men as have possessed the quality of persistence or of stability to resist the disintegrating influence of surrounding circumstances.

In the world of life the naturalist describes those forms which persist as species; similarly the physicist speaks of stable configurations or modes of motion of matter; and the politician speaks of States. The idea at the base of all these conceptions is that of stability, or the power of resisting disintegration. In other words, the degree of persistence or permanence of a species, of a configuration of matter, or of a State depends on the perfection of its adaptation to its surrounding conditions.

If we trace the history of a State we find the degree of its stability gradually changing, slowly rising to a maximum, and then slowly declining. When it falls to nothing a revolution ensues, and a new form of government is established. The new mode of motion or government has at first but slight stability, but it gradually acquires strength and permanence, until in its turn the slow decay of stability leads on to a new revolution.

Such crises in political history may give rise to a condition in which the State is incapable of perpetuation by transformation. This occurs when a savage tribe nearly exterminates another tribe and leads the few survivors into slavery; the previous form of government then becomes extinct.

The physicist, like the biologist and the historian, watches the effect of slowly varying external conditions; he sees the quality of persistence or stability gradually decaying until it vanishes, when there ensues what is called, in politics, a revolution.

These considerations lead me to express a doubt whether biologists have been correct in looking for continuous transformation of species. Judging by analogy, we should rather expect to find slight continuous changes occurring during a long period of time, followed by a somewhat sudden transformation into a new species, or by rapid extinction. However this may be, when the stability of a mode of motion vanishes, the physicist either finds that it is replaced by a new persistent type of motion adapted to the changed conditions, or perhaps that no such transformation is possible, and that the mode of motion has become extinct. The evanescent type of animal life has often been preserved for us, fossilised in geological strata; the evanescent form of government is preserved in written records or in the customs of savage tribes; but the physicist has to pursue his investigations without such useful hints as to the past.

The time-scale in the transmutation of species of animals is furnished by the geological record, although it is not possible to translate that record into years. As we shall see hereafter, the time needed for a change of type in atoms or molecules may be measured by millionths of a second, while in the history of the stars continuous changes may occupy millions of years. Notwithstanding this gigantic contrast in speed, yet the process involved seems to be essentially the same.

It is hardly too much to assert that, if the conditions which determine stability of motion could be accurately formulated throughout the universe, the past history of the cosmos and its future fate would be unfolded. How indefinitely far we stand removed from such a state of knowledge will become abundantly clear from the remainder of my address.

The study of stability and instability then furnishes the problems which the physicist and biologist alike attempt to solve. The two classes of problems differ principally in the fact that the conditions of the world of life are so incomparably more intricate than those of the world of matter that the biologist is compelled to abandon the attempt to determine the absolute amount of the influence of the various causes which have affected the existence of species. His conclusions are merely qualitative and general, and he is almost universally compelled to refrain from asserting even in general terms what are the reasons which have rendered one form of animal life stable and persistent, and another unstable and evanescent.

On the other hand, the physicist, as a general rule, 
does not rest satisfied unless he obtains a quantitative estimate of various causes and effects on the systems of matter. which he discusses. Yet there are some problems of physical evolution in which the conditions are so complex that the physicist is driven, as is the biologist, to rest satisfied with qualitative rather than quantitative conclusions. But he is not content with such crude conclusions except in the last resort, and he generally prefers to proceed by a different method.

The mathematician mentally constructs an ideal mechanical system or model, which is intended to represent in its leading features the system he wants to examine. It is often a task of the utmost difficulty to devise such a model, and the investigator may perchance unconsciously drop out as unimportant something which is really essential to represent actuality. He next examines the conditions of his ideal system, and determines, if he can, all the possible stable and unstable configurations, together with the circumstances which will cause transitions from one to the other. Even when the working model has been successfully imagined, this latter task may often overtax the powers of the mathematician. Finally it remains for him to apply his results to actual matter, and to form a judgment of the extent to which it is justifiable to interpret nature by means of his results.

The remainder of my address will be occupied by an account of various investigations. which will illustrate the principles and methods which I have now explained in general terms.

The fascinating idea that matter of all kinds has a common substratum is of 1emote antiquity. In the Middle Ages the alchemists, inspired by this idea, conceived the possibility of transforming the baser metals into gold. The sole difficulty seemed to them the discovery of an appropriate series of chemical operations. We now know that they were always indefinitely far from the goal of their search, yet we must accord to them the honour of having been the pioneers of modern chemistry.

The object of alchemy, as stated in modern language was to break up or dissociate the atoms of one chemical element into its component parts, and afterwards to reunite them into atoms of gold. Although even the dissociative stage of the alchemistic problem still lies far beyond the power of the chemist, yet modern researches seem to furnish a sufficiently clear idea of the structure of atoms to enable us to see what would have to be done to effect a transformation of elements. Indeed, in the complex changes which are found to occur spontaneously in uranium, radium, and the allied metals we are probably watching a spontaneous dissociation and transmutation of elements.

Natural selection may seem, at first sight, as remote as the poles asunder from the ideas of the alchemist, yet dissociation and transmutation depend on the instability and regained stability of the atom, and the survival of the stable atom depends on the principle of natural selection.

Until some ten years ago the essential diversity of the chemical elements was accepted by the chemist as an ultimate fact, and indeed the very name of atom, or that which cannot be cut, was given to what was supposed to be the final indivisible portion of matter. The chemist hus proceeded in much the same way as the biologist who, in discussing evolution, accepts the species as his working unit. Accordingly, until recently the chemist discussed working models of matter of atomic structure, and the vast edifice of modern chemistry has been built with atomic bricks.

But within the last few years the electrical researches of Lenard, Röntgen, Becquerel, the Curies, of my colleagues Larmor and Thomson, and of a host of others, have shown that the atom is not indivisible, and a flood of light has been thrown thereby on the ultimate constitution of matter. Amongst all these fertile investigators it seems to me that Thomson stands preeminent, because it is principally through him that we are to-day in a better position for picturing the structure of an-atom than was ever the case before.

Even if I had the knowledge requisite for a complete exposition of these investigations, the limits of time would

$$
\text { No. } 1868 \text {, VOL. } 72]
$$

compel me to confine myself to those parts of the subject which bear on the constitution and origin of the elements.

It has been shown, then, that the atom, previously supposed to be indivisible, really consists of a large number of component parts. By various convergent lines of experiment it has been proved that the simplest of all atoms, namely that of hydrogen, consists of about 800 separate parts; while the number of parts in the atom of the denser metals must be counted by tens of thousands. These separate parts of the atom have been called corpuscles or electrons, and may be described as particles of negative electricity. It is paradoxical, yet true, that the physicist knows more about these ultra-atomic corpuscles and can more easily count them than is the case with the atoms of which they form the parts.

The corpuscles, being negatively electrified, repel one another just as the hairs on a person's head mutually repel one another when combed with a vulcanite comb. The mechanism is as yet obscure whereby the mutual repulsion of the negative corpuscles is restrained from breaking up the atom, but a positive electrical charge, or something equivalent thereto, must exist in the atom, so as to prevent disruption. The existence in the atom of this community of negative corpuscles is certain, and we know further that they are moving with speeds which may in some cases be comparable to the velocity of light, namely, 200,000 miles a second. But the mechanism whereby they are held together in a group is hypothetical.

It is only just a year ago that Thomson suggested, as representing the atom, a mechanical or electrical model the properties of which could be accurately examined by mathematical methods. He would be the first to admit that his model is at most merely a crude representation of actuality, yet he has been able to show that such an atom must possess mechanical and electrical properties which simulate, with what Whetham describes as "almost Satanic exactness," some of the most obscure and yet most fundamental properties of the chemical elements. "Se non è vero, è ben trovato," and we are surely justified in believing that we have the clue which the alchemists sought in vain.

Thomson's atom consists of a globe charged with positive electricity, inside which there are some thousand or thousands of corpuscles of negative electricity, revolving in regular orbits with great velocities. Since two electrical charges repel one another if they are of the same kind, and attract one another if they are of opposite kinds, the corpuscles mutually repel one another, but all are attracted by the globe containing them. The forces called into play by these electrical interactions are clearly very complicated, and you will not be surprised to learn that Thomson found himself compelled to limit his detailed examination of the model atom to one containing about seventy corpuscles. It is indeed a triumph of mathematical power to have determined the mechanical conditions of such a miniature planetary system as I have described.

It appears that in general there are definite arrangements of the orbits in which the corpuscles must revolve, if they are to be persistent or stable in their motions. But the number of corpuscles in such a community is not absolutely fixed. It is easy to see that we might add a minor planet, or indeed half a dozen minor planets, to the solar system without any material derangement of the whole; but it would not be possible to add a hundred planets with an aggregate mass equal to that of Jupiter without disorganisation of the solar system. So also we might add or subtract from an atom three or four corpuscles from a system containing a thousand corpuscles moving in regular orbits without any profound derangement. As each arrangement of orbits corresponds to the atom of a distinct element, we may say that the addition or subtraction of a few corpuscles to the atom will not effect a transmutation of elements. An atom which has a deficiency of its full complement of corpuscles, which it will be remembered are negative, will be positively electrified, while one with an excess of corpuscles will be negatively electrified. I have referred to the possibility of a deficiency or excess of corpuscles because it is important in Thomson's theory; but, as it is not involved in the point of view which I wish to take, I will henceforth only refer to the normal or average number in any arrange 
ment of corpuscles. Accordingly we may state that definite numbers of corpuscles are capable of association in stable communities of definite types.

An infinite number of communities are possible, possessing greater or lesser degrees of stability. Thus the corpuscles in one such community might make thousands of revolutions in their orbits before instability declared itself; such an atom might perhaps last for a long time as estimated in millionths of seconds, but it must finally break up and the corpuscles must disperse or re-arrange themselves after the ejection of some of their number. We are thus led to conjecture that the several chemical elements represent those different kinds of communities of corpuscles which have proved by their stability to be successful in the struggle for life. If this is so, it is almost impossible to believe that the successful species have existed for all time, and we must hold that they originated under conditions about which I must forbear to follow Sir Norman Lockyer in speculating. ${ }^{1}$

But if the elements were not eternal in the past, we must ask whether there is reason to believe that they will be eternal in the future. Now, although the conception of the decay of an element and its spontaneous transmutation into another element would have seemed absolutely repugnant to the chemist until recently, yet analogy with other moving systems seems to suggest that the elements are not eternal.

At any rate it is of interest to pursue to its end the history of the model atom which has proved to be so successful in imitating the properties of matter. The laws which govern electricity in motion indicate that such an atom must be radiating or losing energy, and therefore a time must come when it will run down, as a clock does. When this time comes it will spontaneously transmute itself into an element which needs less energy than was required in the former state. Thomson conceives that an atom might be constructed after his model so that its decay should be very slow. It might, he thinks, be made to run for a million years, but it would not be eternal.

Such a conclusion is an absolute contradiction to all that was known of the elements until recently, for no symptoms of decay are perceived, and the elements existing in the solar system must already have lasted for millions of years. Nevertheless, there is good reason to believe that in radium, and in other elements possessing very complex atoms, we do actually observe that break-up and spontaneous re-arrangement which constitute a transmutation of elements.

It is impossible as yet to say how science will solve this difficulty, but future discovery in this field must surely prove deeply interesting. It may well be that the train of thought which I have sketched will ultimately profoundly affect the material side of human life, however remote it may now seem from our experiences of daily life.

I have not as yet made any attempt to represent the excessive minuteness of the corpuscles, of the existence of which we are now so confident; but, as an introduction to what I have to speak of next, it is necessary to do so. To obtain any adequate conception of their size we must betake ourselves to a scheme of threefold magnification. Lord Kelvin has shown that, if a drop of water were magnified to the size of the earth, the molecules of water would be of a size intermediate between that of a cricket-ball and of a marble. Now each molecule contains three atoms, two being of hydrogen and one of oxygen. The molecular system probably presents some sort of analogy with that of a triple star; the three atoms, replacing the stars, revolving about one another in some sort of dance which cannot be exactly described. I doubt whether it is possible to say how large a part of the space occupied by the whole molecule is occupied by the atoms; but perhaps the atoms bear to the molecule some such relationship as the molecule to the drop of water referred to. Finally, the corpuscles may stand to the atom in a similar scale of magnitude. Accordingly a threefold magnification would be needed to bring these ultimate parts of the atom within the range of our ordinary scales of measurement.

I have already considered what would be observed under the triply powerful microscope, and must now return to 1 "Inorganic Evolution." (Macmillan, rgoo.

NO. I 868 , VOL. 72$]$ the intermediate stage of magnification, in which we consider those communities of atoms which form molecules. This is the field of research of the chemist. Although prudence would tell me that it would be wiser not to speak of a subject of which I know so little, yet I cannot refrain from saying a few words.

The community of atoms in water has been compared with a triple star, but there are others known to the chemist in which the atoms are to be counted by fifties and hundreds, so that they resemble constellations.

I conceive that here again we meet with conditions similar to those which we have supposed to exist in the atom. Communities of atoms are called chemical combinations, and we know that they possess every degree of stability. The existence of some is so precarious that the chemist in his laboratory can barely retain them for a moment; others are so stubborn that he can barely break them up. In this case dissociation and re-union into new forms of communities are in incessant and spontaneous progress throughout the world. The more persistent or more stable combinations succeed in their struggle for life, and are found in vast quantities, as in the cases of common salt and of the combinations of silicon. But no one has ever found a mine of gun-cotton, because it has so slight a power of resistance. If, through some accidental collocation of elements, a single molecule of guncotton were formed, it would have but a short life.

Stability is, further, a property of relationship to surrounding conditions; it denotes adaptation to environment. Thus salt is adapted to the struggle for existence on the earth, but it cannot withstand the severer conditions which exist in the sun.

\section{SECTION A.}

MATHEMATICS AND PHYSICS.

Opening Address by Prof. A. R. Forsyth, Sc.D., Ll.D., Math.D., F.R.S., President of the Section.

According to an established and unchallenged custom, our proceedings are inaugurated by an address from the President. Let me begin it by discharging a duty which, unhappily, is of regular recurrence. If your President only mentions names when he records the personal losses suffered during the year by the sciences of the Section, the corporate sense of the Section will be able to appreciate the losses with a deeper reality than can be conveyed by mere words.

In $\mathrm{Mr}$. Ronald Hudson, who was one of our secretaries at the Cambridge meeting a year ago, we have lost a mathematician whose youthful promise had ripened into early performance. The original work which he had accomplished is sufficient, both in quality and in amount, to show that much has been given, and that much more could have been expected. His alert and bright personality suggested that many happy years lay before him. All these fair hopes were shattered in a moment by an accident upon a Welsh hillside; and his friends, who were many, deplore his too early death at the age of twenty-eight.

The death of Mr. Frank McClean has robbed astronomy of one of its most patient workers and actively creative investigators. I wish that my own knowledge could enable me to give some not inadequate exposition of his services to the science which he loved so well. He was a man of great generosity which was wise, discriminating, and more than modest; to wide interests in science he united wide interests in the fine arts. Your Astronomer Royal, in the Royal Observatory at Cape Town, will not lightly forget his gift of a great telescope; and the University of Cambridge, the grateful recipient of his munificent endowment of the Isaac Newton Studentships fifteen years ago, and of his no less munificent bequest of manuscripts, early printed books, and objects of art, has done what she can towards perpetuating his memory for future generations by including his name in the list, that is annually recited in solemn service, of her benefactors who have departed this life.

In the early days of our gatherings, when the set of cognate sciences with which we specially are concerned had not yet diverged so widely from one another alike in subject and in method, this inaugurating address was sharacterised by a brevity that a President can envy and 
by a freedom from formality that even the least tolerant audience could find admirable. The lapse of time, perhaps assisted by presidential ambitions which have been veiled under an almost periodic apology for personal shortcomings, has deprived these addresses of their ancient brevity, and has invested them with an air of oracular gravity. The topics vary from year to year, but this variation is due to the predilection of the individual Presidents; the types of address are but few in number. Sometimes, indeed, we have had addresses that cannot be ranged under any comprehensive type. Thus one year we had an account of a particular school of long-sustained consecutive research; another year the President made a constructive (and perhaps defiant) defence of the merits of a group of subjects that were of special interest to himself. But there is one type of address which recurs with iterated frequency; it is constituted by a general account of recent progress in discovery, or by a survey of modern advances in some one or other of the branches of science to which the multiple activities of our Section are devoted. No modern President has attempted a general survey of recent progress in all the branches of our group of sciences; such an attempt will probably be deferred until the Council discovers a President who, endowed with the omniscience of a Whewell, and graced with the tongue of men and of angels, shall once again unify our discussions.

On the basis of this practice, it would have been not unreasonable on my part to have selected some topic from the vast range of pure mathematics, and to have expounded some body of recent investigations. There certainly is no lack of topics; our own day is peculiarly active in many directions. Thus, even if we leave on one side the general progress that has been made in many of the large branches of mathematics during recent years, it is easy to hint at numerous subjects which could occupv the address of a mathematical President. He might, for instance, devote his attention to modern views of continuity, whether of quantity or of space; he might be heterodox or orthodox as to the so-called laws of motion; he might expound his notions as to the nature and properties of analytic functionality; a discussion of the hypotheses upon which a consistent system of geometry can be framed could be made as monumental as his ambition might choose; he could revel in an account of the most recent philosophical analysis of the foundations of mathematics, even of logic itself, in which all axioms must either be proved or be compounded of notions that defy resolution by the human intellect at the present day. Such discussions are bound to be excessively technical unless they are expressed in unmathematical phraseology; when they are so expressed, and in so far as such expression is possible, they become very long and they can be very thin. Moreover, had I chosen any topic of this character, it would have been the merest natural justice to have given early utterance of the sibyllic warning to the uninitiated; I must also have bidden the initiated that, as they come, they should summon all the courage of their souls. So I abstain from making such an experiment upon an unwarned audience; yet it is with reluctance that I have avoided subjects in the range which to me is of peculiar interest.

On the other hand, I must ask your indulgence for not conforming to average practice and expectation. My desire is to mark the present occasion by an address of unspecialised type which, while it is bound to be mainly mathematical in tenor, and while it will contain no new information, may do little more than recall some facts that are known, and will comment briefly upon obvious tendencies. Let me beg you to believe that it is no straining after novelty which has dictated my choice; such an ambition has a hateful facility of being fatal both to the performer and to the purpose. It is the strangeness of our circumstances, both in place and time, that has suggested my subject. With an adventurous audacity that quite overcrows the spirit of any of its past enterprises, the British Association for the Advancement of Science has travelled south of the Equator and, in accepting your hospitality, proposes to traverse much of South Africa. The prophet of old declared that "many shall run to and fro, and knowledge shall be increased "; if the second part of the prophecy is not fulfilled, it will not be for the want of our efforts to fulfil the first part. And if the place and the range of this peripatetic demonstration of our annual corporate activity are unusual, the occasion chosen for this enterprise recalls memories that are fundamental in relation to our subject. It is a modern fashion to observe centenaries. In this section we are in the unusual position of being able to observe three scientific centenaries in one and the same year. Accordingly I propose to refer to these in turn, and to indicate a few of the events filling the intervals between them; but my outline can be of only the most summary character, for the scientific history is a history of three hundred years, and, if searching enough, it could include the tale of nearly all mathematical and astronomical and physical science.

It is exactly three hundred years since Bacon published "The Advancement of Learning." His discourse, alike in matter, in thought, in outlook, was in advance of its time, and it exercised no great influence for the years that immediately followed its appearance; yet that appearance is one of the chief events in the origins of modern natural science. Taking all knowledge to be his province, he surveys the whole of learning: he deals with the discredits that then could attach to it; he expounds both the dignity and the influence of its pursuit; and he analyses all learning, whether of things divine or of things human, into its ordered branches. He points out deficiencies and gaps; not a few of his recommendations of studies, at his day remaining untouched, have since become great branches of human thought and human inquiry. But what concerns us most here is his attitude towards natural philosophy, all the more remarkable because of the state of knowledge of that subject in his day, particularly in England. It is true that Gilbert had published his discovery of terrestrial magnetism some five years earlier, a discovery followed only too soon by his death; but that was the single considerable English achievement in modern science down to Bacon's day.

In order to estimate the significance of Bacon's range of thought let me recite a few facts, as an indication of the extreme tenuity of progressive science in that year (1605). They belong to subsequent years, and may serve to show how restricted were the attainments of the period, and how limited were the means of advance. The telescope and the microscope had not yet been invented. The simple laws of planetary motion were not formulated, for Kepler had them only in the making. Logarithms were yet to be discovered by Napier, and to be calculated by Briggs. Descartes was a boy of nine and Fermat a boy of only four, so that analytical geometry, the middle-life discovery of both of them, was not yet even a dream for either of them. The Italian mathematicians, of whom Cavalieri is the least forgotten, were developing Greek methods of quadrature by a transformed principle of indivisibles; but the infinitesimal calculus was not really in sight, for Newton and Leibnitz were yet unborn. Years were to elapse before, by the ecclesiastical tyranny over thought, Galileo was forced to make a verbal disavowal of his adhesion to the Copernican system of astronomy, of which he was still to be the protagonist in propounding any reasoned proof. Some mathematics could be had, cumbrous arithmetic and algebra, some geometry lumbering after Euclid, and a little trigonometry; but these were mainly the mathematics of the Renaissance, no very great advance upon the translated work of the Greeks and the transmitted work of the Arabs. Even our old friend the binomial theorem, which now is supposed to be the possession of nearly every able schoolboy, remained unknown to professional mathematicians for more than half a century yet to come.

Nor is it merely on the negative side that the times seemed unpropitious for a new departure; the spirit of the age in the positive activities of thought and deed was not more sympathetic. Those were the days when the applications of astronomy had become astrology. Men sought for the elixir of life and pondered over the transmutation of baser metals into gold. Shakespeare not long before had produced his play As You Like It, where the strange natural history of the toad which, "Ugly and venomons,

Bears yet a precious jewel in his head."

is made a metaphor to illustrate the sweetening uses of adversity. The stiffened Elizabethan laws against witch-

NO. I 868, VOL. 72] 
craft were to be sternly administered for many a year to come. It was an age that was pulsating with life and illuminated by fancy, but the life was the life of strong action and the fancy was the fancy of ideal imagination; men did not lend themselves to sustained and abstract thought concerning the nature of the universe. When we contemplate the spirit that such a state of knowledge might foster towards scientific learning, and when we recall the world into which Bacon's treatise was launched, we can well be surprised at his far-reaching views, and we can marvel at his isolated wisdom.

Let me select a few specimens of his judgments, chosen solely in relation to our own subjects. When he says :

"All true and fruitful natural philosophy hath a double scale or ladder, ascendant and descendant, ascending from experiments to the invention of causes, and descending from causes to the invention of new experiments; therefore I judge it most requisite that these two parts be severally considered and handled "-

he is merely expounding, in what now is rather archaic phrase, the principles of the most ambitious investigations in the natural philosophy of subsequent centuries. When he speaks of

"the operation of the relative and adventive characters of essences, as quantity, similitude, diversity, possibility, and the rest; with this distinction and provision, that they be handled as they have efficacy in nature, and not logically ".

I seem to hear the voice of the applied mathematician warning the pure mathematician off the field. When, after having divided natural philosophy into physic and metaphysic (using these words in particular meanings, and including mathematics in the second of the divisions), he declares

"physic should contemplate that which is inherent in matter, and therefore transitory, and metaphysic that which is abstracted and fixed; .... physic describeth the causes of things, but the variable or respective causes; and metaphysic the fixed and constant causes "-

there comes before my mind the army of physicists of the present day, who devote themselves unwearyingly to the properties of matter and willingly cast aside elaborate arguments and calculations. When he argues that

" many parts of nature can neither be invented with sufficient subtilty, nor demonstrated with sufficient perspicuity, nor accommodated unto use with sufficient dexterity, without the aid and intervening of the mathematics "-

he might be describing the activity of subsequent generations of philosophers, astronomers, and engineers. And in the last place (for my extracts must have some end), when he expresses the opinion

" that men do not sufficiently understand the excellent use of the pure mathematics, in that they do remedy and cure many defects in the wit and faculties intellectual. For if the wit be too dull, they sharpen it; if too wandering, they fix it; if too inherent in the sense, they abstract it ; . . . in the mathematics, that which is collateral and intervenient is no less worthy than that which is principal and intended "-

I seem to hear an advocate for the inclusion of elementary mathematics in any scheme of general education. At the same time, I wonder what Bacon, who held such an exalted estimate of pure mathematics in its grey dawn, would have said by way of ampler praise of the subject in its fuller day.

It was a splendid vision of inductive science as of other parts of learning; it contained a revelation of the course of progress through the centuries to come. Yet the facts of to-day are vaster than the vision of that long-ago yesterday, and human activity has far outstripped the dreams of Bacon's opulent imagination. $\mathrm{He}$ was the harbinger (premature in many respects it must be confessed, but still the harbinger) of a new era. At a time when we are making a new departure in the fulfilment of the purpose of our charter, which requires us " to promote the intercourse of those who cultivate Science in different parts of the British Empire," our Association for the Advancement of Science may pause for a moment to gaze upon the vision revealed three centuries ago in the "Advancement of Learning" by a philosopher whose influence upon the thought of the world is one of the glories of our nation.

I have implied that Bacon's discourse was in advance of its age, so far as England was concerned. Individuals could make their mark in isolated fashion. Thus Harvey, in his hospital work in London, discovered the circulation of the blood; Napier, away on his Scottish estates, invented logarithms; and Horrocks, in the seclusion of a Lancashire curacy, was the first to observe a transit of Venus. But for more than half a century the growth of physical science was mainly due to workers on the continent of Europe. Galileo was making discoveries in the mechanics of solids and fluids, and, specially, he was building on a firm foundation the fabric of the system of astronomy, hazarded nearly a century before by Copernicus; he still was to furnish, by bitter experience, one of the most striking examples in the history of the world that truth is stronger than dogma. Kepler was gradually elucidating the laws of planetary motion, of which such significant use was made later by Newton; and Descartes, by his creation of analytical geometry, was yet to effect such a constructive revolution in mathematics that he might not unfairly be called the founder of modern mathematics. In England the times were out of scientific joint; the political distractions of the Stuart troubles, and the narrow theological bitterness of the Commonwealth, made a poor atmosphere for the progress of scientific learning, which was confined almost to a faithful few. The fidelity of those few, however, had its reward; it was owing to their steady confidence and to their initiative that the Royal Society of London was founded in 1662 by Charles II. At that epoch, science (to quote the words of a picturesque historian) became the fashion of the day. Great Britain began to contribute at least her fitting share to the growing knowledge of Nature; and her scientific activity in the closing part of the seventeenth century was a realisation, wonderful and practical, of a part of Bacon's dream. Undoubtedly the most striking contribution made in that period is Newton's theory of gravitation, as expounded in his "Principia," published in I687.

That century also saw the discovery of the fluxional calculus by Newton, and of the differential calculus by Leibnitz. These discoveries provided the material for one of the longest and most deadening controversies as to priority in all the long history of those tediously barren occupations; unfortunately they are dear to minds which cannot understand that a discovery should be used, developed, amplified, but should not be a cause of envy, quarrel, or controversy. Let me say, incidentally, that the controversy had a malign influence upon the study of mathematics as pursued in England.

Also, the undulatory theory of light found its first systematic, if incomplete, exposition in the work of Huygens before the century was out. But Newton had an emission theory of his own, and so the undulatory theory of Huygens found no favour in England until rather more than a hundred years later; the researches of Thomas Young established it on a firm foundation.

Having thus noted some part of the stir in scientific life which marked the late years of the seventeenth century, let me pass to the second of our centenaries; it belongs to the name of Edmond Halley. Quite independently of his achievement connected with the year 1705 to which I am about to refer, there are special reasons for honouring Halley's name in this section at our meeting in South Africa. . When a young man of twenty-one he left England for St. Helena, and there, in the years $1676-1678$, he laid the foundations of stellar astronomy for the Southern Hemisphere; moreover, in the course of his work he there succeeded in securing the first complete observation of a transit of Mercury. After his return to England, the next few years of his life were spent in laying science under a special debt that can hardly be over-appreciated. $\mathrm{He}$ placed himself in personal relation with Newton, propounded to him questions and offered information; and it is now. a commonplace statement that Halley's questions and suggestions caused Newton to write the "Principia."

NO. I 868, VOL. 72 ] 
More than this, we know that Newton's great treatise saw the light only through Halley's persuasive insistence, through his unwearying diligence in saving Newton all cares and trouble and even pecuniary expense, and through his absolutely self-sacrificing devotion to what he made an unwavering duty at that epoch in his life. Again, he appears to have been the first organiser of a scientific expedition, as distinct from a journey of discovery, towards the Southern Seas; he sailed as far as the fifty-second degree of southern latitude, devised the principle of the sextant in the course of his voyaging, and, as a result of the voyage, he produced a General Chart of the Atlantic Ocean, with special reference to the deviation of the compass. Original, touched with genius, cheery of soul, strenuous in thought and generous by nature, he spent his life in a continuously productive devotion to astronomical science, from boyhood to a span of years far beyond that which satisfied the Psalmist's broodings. ] have selected a characteristic incident in his scientific activity, one of the most brilliant (though it cannot be claimed as the most important) of his astronomical achievements; it strikes me as one of the most chivalrously bold acts of convinced science within my knowledge. It is only the story of a comet.

I have just explained, very briefly, Halley's share in the production of Newton's "Principia"; his close concern with it made him the Mahomet of the new dispensation of the astronomical universe, and he was prepared to view all its phenomena in the light of that dispensation. A comet had appeared in $1682-$ it was still the age when scientific men could think that, by a collision between the earth and a comet, "this most beautiful order of things would be entirely destroyed and reduced to its ancient chaos "; but this fear was taken as a " by-the-bye," which happily interfered with neither observations nor calculations. Observations had duly been made. The data were used to obtain the elements of the orbit, employing Newton's theory as a working hypothesis; and he expresses an incidental regret as to the intrinsic errors of assumed numerical elements and of recorded observations. It then occurred to Halley to calculate similarly the elements of the comet which Kepler and others had seen in 1607 , and of which records had been made; the Newtonian theory gave elements in close accord with those belonging to the comet calculated from the latest observations, though a new regret is expressed that the 1607 observations had not been made with more accuracy. On these results he committed himself (being then a man of forty-nine years of age) to a prophecy (which could not be checked for fiftythree years to come) that the comet would return about the end of the year $175^{8}$ or the beginning of the next succeeding year; he was willing to leave his conclusion "to be discussed by the care of posterity, after the truth is found out by the event." But not completely content with this stage of his work, he obtained with difficulty a book by Apian, giving an account of a comet seen in I53 I and recording a number of observations. Halley, constant to his faith in the Newtonian hypothesis, used that hypothesis to calculate the elements of the orbit of the Apian comet; once more regretting the uncertainty of the data and discounting a very grievous error committed by Apian himself, Halley concluded that the Apian comet of I53I, and the Kepler comet of 1607 , and the observed comet of 1682 were one and the same. He confirmed his prediction as to the date of its return, and he concludes his argument with a blend of confidence and patriotism :-

"Wherefore if according to what we have already said it should return again about the year 1758 , candid posterity will not refuse to acknowledge that this was first discovered by an Englishman."

Such was Halley's prediction published in the year 1705 . The comet pursued its course, and it was next seen on Christmas Day, I758. Candid posterity, so far from refusing to acknowledge that the discovery was made by an Englishman, has linked Halley's name with the comet, possibly for all time.

We all now could make announcements on the subject of Halley's comet; their fulfilment could be awaited serenely. No vision or inspiration is needed; calculations NO. I 868 , VOL. 72$]$ and corrections will suffice. The comet was seen in 1835 , and it is expected again in 1910. No doubt our astronomers will be ready for it; and the added knowledge of electrical science, in connection particularly with the properties of matter, may enable them to review Bessel's often-discussed conjecture as to an explanation of the emission of a sunward tail. But Halley's announcement was made during what may be called the immaturity of the gravitation theory; the realisation of the prediction did much to strengthen the belief in the theory and to spread its general acceptance; the crown of conviction was attained with the work of Adams and Leverrier in the discovery, propounded by theory and verified by observation, of the planet Neptune. I do not know an apter illustration of Bacon's dictum that has already been quoted, "All true and fruitful natural philosophy hath a double scale, ascending from experiments to the invention of causes, and descending from causes to the invention of new experiments." The double process, when it can be carried out, is one of the most effective agents for the increase of trustworthy knowledge. But until the event justified Halley's prediction, the Cartesian vortex-theory of the universe was not completely replaced by the Newtonian theory; the Cartesian votaries were not at once prepared to obey Halley's jubilant, if stern, injunction to "leave off trifling... with their vortices and their absolute plenum ... and give themselves up to the study of truth."

The century that followed the publication of Halley's prediction shows a world that is steadily engaged in the development of the inductive sciences and their applications. Observational astronomy continued its activity quite steadily, reinforced towards the end of the century by the first of the Herschels. 'The science of mathematical (or theoretical) astronomy was created in a form that is used to this day; but before this creation could be effected, there had to be a development of mathematics suitable for the purpose. The beginnings were made by the Bernoullis (a family that must be of supreme interest to Dr. Francis Galton in his latest statistical compilations, for it contained no fewer than seven mathematicians of mark, distributed over three generations), but the main achievements are due to Euler, Lagrange, and Laplace. In particular, the infinitesimal calculus in its various branches (including, that is to say, what we call the differential calculus, the integral calculus, and differential equations) received the development that now is familiar to all who have occasion to work in the subject. When this calculus was developed, it was applied to a variety of subjects; the applications, indeed, not merely influenced, but immediately directed, the development of the mathematics. To this period is due the construction of analytical mechanics at the hands of Euler, d'Alembert, Lagrange, and Poisson; but the most significant achievement in this range of thought is the mathematical development of the Newtonian theory of gravitation applied to the whole universe. It was made, in the main, by Lagrange, as regards the wider theory, and by Laplace, as regards the amplitude of detailed application. But it was a century that also saw the obliteration of the ancient doctrines of caloric and phlogiston, through the discoveries of Rumford and Davy of the nature and relations of heat. The modern science of vibrations had its beginnings in the experiments of Chladni, and, as has already been stated, the undulatory theory of light was rehabilitated by the researches of 'Thomas Young. Strange views as to the physical constitution of the universe then were sent to the limbo of forgotten ignorance by the early discoveries of modern chemistry; and engineering assumed a systematic and scientific activity, the limits of which seem bounded only by the cumulative ingenuity of successive generations. But in thus attempting to summarise the progress of science in that period, I appear to be trespassing upon the domains of other Sections; my steps had better be retraced so as to let us return to our own upper air. If. I mention one more fact (and it will be a small one), it is because of its special connection with the work of this Section. As you are aware, the elements of Euclid have long been the standard treatise of elementary geometry in Great Britain ; and the Greek methods, in Robert Simson's edition, have been imposed upon candidates in examination after ex- 
amination. But Euclid is on the verge of being disestablished; my own University of Cambridge, which has had its full share in maintaining the restriction to Euclid's methods, and which was not uninfluenced by the report of a Committee of this Association upon the subject, will, some six or seven weeks hence, hold its last examination in which those methods are prescriptively required. The disestablishment of Euclid from tyranny over the youthful student on the continent of Europe was effected before the end of the eighteenth century.

But it is time for me to pass on to the third of the centenaries, with which the present year can be associated. Not so fundamental for the initiation of modern science as was the year in which the "Advancement of Learning" was published, not so romantic in the progress of modern science as was the year in which Halley gave his prediction to the world, the year 1805 (turbulent as it was with the strife of European politics) is marked by the silent voices of a couple of scientific records. In that year Laplace published the last progressive instalment of his great treatise on Celestial Mechanics, the portion that still remained for the future being solely of an historical character; the great number of astronomical phenomena which he had been able to explain by his mathematical presentation of the consequences of the Newtonian theory would, by themselves, have been sufficient to give confidence in the validity of that theory. In that year also Monge published his treatise, classical and still to be read by all students of the subject, "The Application of Algebra to Geometry "; it is the starting point of modern synthetic geometry, which has marched in ample development since his day. These are but landmarks in the history of mathematical science, one of them indicating the completed attainment of a tremendous task, the other of them initiating a new departure; both of them have their significance in the progress of their respective sciences.

When we contemplate the activity and the achievements of the century that has elapsed since the stages which have just been mentioned were attained in mathematical science, the amount, the variety, the progressive diligence, are little less than bewildering. It is not merely the vast development of all the sciences that calls for remark; no less striking is their detailed development. Each branch of science now has an enormous array of workers, a development rendered more easily possible by the growing increase in the number of professional posts; and through the influence of these workers and their labours there is an ever-increasing body of scientific facts. Yet an aggregate of facts is not an explanatory theory any more necessarily than a pile of carefully fashioned stones is a cathedral; and the genius of a Kepler and a Newton is just as absolutely needed to evolve the comprehending theory as the genius of great architects was needed for the Gothic cathedrals of France and of England. Not infrequently it is difficult to make out what is the main line of progress in any one subject, let alore in a group of subjects; and though illumination comes from striking results that appeal, not merely to the professional workers, but also to unprofessional observers, this illumination is the exception rather than the rule. We can allow, and we should continue to allow, freedom of initiative in all directions. That freedom sometimes means isolation, and its undue exercise can lead to narrowness of view. In spite of the complex ramification of the sciences which it has fostered, it is a safer and a wiser spirit than that of uncongenial compulsion, which can be as dogmatic in matters scientific as it can be in matters theological. Owing to the varieties of mind, whether in individuals or in races, the progress of thought and the growth of knowledge are not ultimately governed by the wishes of any individual or the prejudices of any section of individuals. Here, a school of growing thought may be ignored; there, it may be denounced as of no importance; somewhere slse, it may be politely persecuted out of possible existence. But the here, and the there, and the somewhere else do not make up the universe of human activity; and that school, like Galileo's earth in defiance of all dogmatic authority, still will move.

This complete freedom in the development of scientific thought, when the thought is applied to natural phenomena, is all the more necessary because of the ways of
Nature. Physical nature cares nothing for theories, nothing for calculations, nothing for difficulties, whatever their source; she will only give facts in answer to our questions, without reasons and without explanations; we may explain as we please and evolve laws as we like, without her help or her hindrance. If from our explanations and our laws we proceed to prediction, and if the event justifies the prediction through agreement with recorded fact, well and good; so far we have a working hypothesis. The significance of working hypotheses, in respect of their validity and their relation to causes, is a well known battle-ground of dispute between different schools of philosophers; it need not detain us here and now. On the other hand, when we proceed from our explanations and our laws to a prediction, and the prediction in the end does not agree with the fact to be recorded, it is the prediction that has to give way. But the old facts remain and the new fact is added to them; and so facts grow until some working law can be extracted from them. This accumulation of facts is only one process in the solution of the universe; when the compelling genius is not at hand to transform knowledge into wisdom, useful work can still be done upon them by the construction of organised accounts which shall give a systematic exposition of the results, and shall place them as far as may be in relative significance.

Let me pass from these generalities, which have been suggested to my mind by the consideration of some of the scientific changes that have taken place during the last hundred years, and let me refer briefly to some of the changes and advances which appear to me to be most characteristic of that period. It is not that I am concerned with a selection of the most important researches of the period. Estimates of relative importance are often little more than half-concealed expressions of individual preferences or personal enthusiasms; and though each enthusiastic worker, if quite frank in expressing his opinion, would declare his own subject to be of supreme importance, he would agree to a compromise that the divergence between the different subjects is now so wide as to have destroyed any common measure of comparison. $\mathrm{My}$ concern is rather with changes, and with tendencies where these can be discerned.

The growth of astronomy has already occupied so large a share of my remarks that few more words can be spared here. Not less, but more, remarkable than the preceding centuries in the actual exploration of the heavens, which has been facilitated so much by the improvements in instruments and is reinforced to such effect by the cooperation of an ever-growing band of American astronomers, it has seen a new astronomy occupy regions undreamt of in the older days. New methods have supplemented the old; spectroscopy has developed a science of physics within astronomy; and the unastronomical brain reels at the contents of the photographic chart of the heavens which is now being constructed by international cooperation and will, when completed, attempt to map ten million stars (more or less) for the human eye.

Nor has the progress of physics, alike on the mathematical side and the experimental side, been less remarkable or more restricted than that of astronomy. The elaborate and occasionally fantastic theories of the eighteenth century, in such subjects as light, heat, even as to matter itself, were rejected in favour of simpler and more comprehensive theories. There was one stage when it seemed as if the mathematical physicists were gradually overtaking the experimental physicists; but the discoveries in electricity begun by Faraday left the mathematicians far behind. Much has been done towards the old duty, ever insistent, of explaining new phenomena; and the names of Maxwell, Weber, Neumann, and Hertz need only to be mentioned in order to suggest the progress that has been made in one subject alone. We need not hesitate to let our thoughts couple, with the great physicists of the century, the leaders of that brilliant band of workers upon the properties of matter who carry us on from wonder to wonder with the passage of each successive year.

Further, it has been an age when technical applications have marched at a marvellous pace. So great has been their growth that we are apt to forget their comparative youth; yet it was only the middle of the century which 
saw the awakening from what now might be regarded as the dark ages. Nor is the field of possible application nearing exhaustion; on the contrary, it seems to be increasing by reason of new discoveries in pure science that yet will find some beneficent outcome in practice. Invisible rays and wireless telegraphy may be cited as instances that are occupying present activities, not to speak of radium, the unfolding of the future of which is watched by eager minds.

One gap, indeed, in this subject strikes me. There are great histories of mathematics and great histories of astronomy; I can find no history of physics on the grand scale. Some serviceable manuals there are, as well as monographs on particular topics; what seems to me to be lacking is some comprehensive and comparative survey of the whole range. The history of any of the natural sciences, like the history of human activity, is not merely an encyclopædic record of past facts; it reveals both the spirit and the wealth which the past has bequeathed to the present, and which, in due course, the present will influence before transmission to the future. Perhaps all our physicists are too busy to spare the labour needed for the production of a comprehensive history; yet I cannot help thinking that such a contribution to the subject would be of great value, not to physicists alone.

But, as you hear me thus referring to astronomy and to physics, some of you may think of the old Roman proverb which bade the cobbler not to look above his last; so I take the opportunity of referring very briefly to my own subject. One of the features of the century has been the continued development of mathematics. As a means of calculation the subject was developed as widely during the earlier portion of the century as during the preceding century; it soon began to show signs of emergence as an independent science, and the later part of the century has witnessed the emancipation of pure mathematics. It was pointed out, in connection with the growth of theoretical astronomy, that mathematics developed in the direction of its application to that subject. When the wonderful school of French physicists, composed of Monge, Carnot, Fourier, Poisson, Poinsot, Ampère, and Fresnel (to mention only some names), together with Gauss, Kirchhoff, and von Helmholtz in Germany, and Ivory, Green, Stokes, Maxwell, and others in England, applied their mathematics to various branches of physics, for the most part its development was that of an ancillary subject. The result is the superb body of knowledge that may be summarised under the title of "mathematical physics" ; but the final interest is the interest of physics, though the construction has been the service of mathematics. Moreover, this tendency was deliberate, and was avowed in no uncertain tone. Thus Fourier could praise the utility of mathematics by declaring that "there was no language more universal or simpler, more free from errors or obscurity, more worthy of expressing the unchanging relations of natural entities"; in a burst of enthusiasm he deciares that, from the point of view he had indicated, "mathematical analysis is as wide as Nature herself," and "it increases and grows incessantly stronger amid all the changes and errors of the human mind." Mathematicians might almost blush with conscious pleasure at such a laudation of their subject from such a quarter, though it errs both by excess and defect; but the exultation of spirit need not last long. The same authority, when officially expounding to the French Academy the work of Jacobi and of Abel upon elliptic functions, expressed his chilling opinion (it had nothing to do with the case) that "the questions of natural philosophy, which have the mathematical study of all important phenomena, for their aim, are also a worthy and principal subject for the meditations of geometers. It is to be desired that those persons who are best fitted to improve the science of calculation should direct their labours to these important applications." Abel was soon to pass beyond the range of admonition; but Jacobi, in a private letter to Legendre, protested that the scope of the science was not to be limited to the explanation of natural phenomena. I have not quoted these extracts by way of even hint of reproach against the author of such a wonderful creation as Fourier's analytical theory of heat; his estimate could have been justified on a merely historical review of the circumstances of his own time and of past times; and I am not sure that his estimate has not its exponents at the present day. But all history shows that new discoveries and new methods can spread to issues wider than those of their origins, and that it is almost a duty of human intelligence to recognise this possibility in the domain of progressive studies. The fact is that mathematical physics and pure mathematics have given much to each other in the past and will give much to each other in the future; in doing so, they will take harmonised action in furthering the progress of knowledge. But neither science must pretend to absorb the activity of the other. It is almost an irony of circumstance that a theorem, initiated by Fourier in the treatise just mentioned, has given rise to a vast amount of discussion and attention, which, while of supreme value in the development of one branch of pure mathematics, have hitherto offered little, if anything, by way of added explanation of natural phenomena.

The century that has gone has witnessed a wonderful development of pure mathematics. The bead-roll of names in that science-Gauss; Abel, Jacobi; Cauchy, Riemann, Weierstrass, Hermite; Cayley, Sylvester; Lobatchewsky, Lie-will on only the merest recollection of the work with which their names are associated show that an age has been reached where the development of human thought is deemed as worthy a scientific occupation of the human mind as the most profound study of the phenomena of the material universe.

The last feature of the century that will be mentioned has been the increase in the number of subjects, apparently dissimilar from one another, which are now being made to use mathematics to some extent. Perhaps the most surprising is the application of mathematics to the domain of pure thought; this was effected by George Boole in his treatise "Laws of Thought," published in 1854; and though the developments have passed considerably beyond Boole's researches, his work is one of those classics that mark a new departure. Political economy, on the initiative of Cournot and Jevons, has begun to employ symbols and to develop the graphical methods; but, there, the present use seems to be one of suggestive record and expression, rather than of positive construction. Chemistry, in a modern spirit, is stretching out into mathematical theories; Willard Gibbs, in his memoir on the equilibrium of chemical systems, has led the way; and, though his way is a path which chemists find strewn with the thorns of analysis, his work has rendered, incidentally, a real service in coordinating experimental results belonging to physics and to chemistry. A new and generalised theory of statistics is being constructed; and a school has grown up which is applying them to biological phenomena. Its activity, however, has not yet met with the sympathetic goodwill of all the pure biologists; and those who remember the quality of the discussion that took place last year at Cambridge between the biometricians and some of the biologists will agree that, if the new school should languish, it will not be for want of the tonic of criticism

If I have dealt with the past history of some of the sciences with which our. Section is concerned, and have chosen particular epochs in that history with the aim of concentrating your attention upon them, you will hardly expect me to plunge into the future. Being neither a prophet nor the son of a prophet, not being possessed of the knowledge which enabled Halley to don the prophet's mantle with confidence, I shall venture upon no prophecy even so cautious as Bacon's-" As for the mixed mathematics I may only make this prediction, that there cannot fail to be more kinds of them as Nature grows further disclosed"-a declaration that is sage enough, though a trifle lacking in precision. Prophecy, unless based upon confident knowledge, has passed out of vogue, except perhaps in controversial politics; even in that domain, it is helpless to secure its own fulfilment. Let me rather exercise the privilege of one who is not entirely unfamiliar with the practice of geometry, and let me draw the proverbial line before indulgence in prophetic estimates. The names that have flitted through my remarks, the discoveries and the places associated with those names, definitely indicate that, notwithstanding all appearance of 
divergence and in spite of scattered isolation, the sum of human knowledge, which is an inheritance common to us all, grows silently, sometimes slowly, yet (as we hope) safely and surely, through the ages. You who are in South Africa have made an honourable and an honoured contribution to that growing knowledge, conspicuously in your astronomy and through a brilliant succession of astronomers. Here, not as an individual but as a representative officer of our brotherhood in the British Association, I can offer you no better wish than that you may produce some men of genius and a multitude of able workers who, by their researches in our sciences, may add to the fame of your country and will contribute to the intellectual progress of the world.

\section{SECTION B.}

\section{CHEMISTRY.}

Opening Address by G. T. Beilby, President of thr Section.

IN scanning the list of the elements with which we are thoughtfully supplied every year by the International Committee on Atomic Weights, the direction in which our thoughts are led will depend on the particular aspect of chemical study which happens to interest us at the time. Putting from our minds on the present occasion the attractive speculations on atomic constitution and disintegration with which we have all become at least superficially familiar during the past few years, let us try to scan this list from the point of view of the "plain man" rather than from that of the expert chemist. Even a rudimentary knowledge will be sufficient to enable our "plain man" to divide the elements broadly into two groups-the actually useful and the doubtfully useful or useless. Without going into detail we may take it that about two-thirds would be admitted into the first group, and one-third into the second. It must, I think, be regarded as a very remarkable fact that of the eighty elements which have had the intrinsic stability to enable them to survive the prodigious forces which must have been concerned in the evolution of the physical universe, so large a proportion are endowed with characteristic properties which could ill have been spared either from the laboratories of Nature or from those of the Arts and Sciences. Even if one-third of the elements are to be regarded as waste products or failures, there is here no counterpart to the reckless prodigality of Nature in the processes of organic evolution.

If we exclude those elements which participate directly and indirectly in the structure and functions of the organic world, there are two elements which stand out conspicuously because of the supreme influence they have exercised over the trend of human effort and ambition. I refer, of course, to the metals gold and iron.

From the early beginnings of civilisation gold has been highly prized and eagerly sought after. Human life has been freely sacrificed in its acquirement from natural sources, as well as in its forcible seizure from those who already possessed it. The "Age of Gold" was not necessarily "The Golden Age," for the noble metal in its unique and barbaric splendour has symbolised much that has been unworthy in national and individual aims and ideals.

We have accustomed ourselves to think of the present as the Age of Iron, as indeed it is, for we see in the dull, grey metal the plastic medium out of which the engineer has modelled the machines and structures which play so large a part in the active life of to-day. Had iron not been at once plentiful and cheap, had it not brought into the hands of the engineer and artificer its marvellous qualities of hardness and softness, of rigidity and toughness, and to the electrician its mysterious and unique magnetic qualities, it is not difficult to conceive that man's control over the forces of Nature might have been delayed for centuries, or perhaps for ages. For iron has been man's chief material instrument in the conquest of Nature ; without it the energy alike of the waterfall and of the coalfield would have remained uncontrolled and unused. In this conquest of the resources of Nature for the service of man are we not entitled to say that the intellectual NO. 1868 , vOI.. 72$]$ and social gains hare equalled, if they have not exceeded, in value the purely material gains; and may we not then regard iron as the symbol of a beneficent conquest of Nature?

With the advent of the Industrial Age gold was destined to take a new place in the world's history as the great medium of exchange, the great promoter of industry and commerce. While individual gain still remained the propelling power towards its discovery and acquisition, every fresh discovery led directly or indirectly to the freer interchange of the products of industry, and thus reacted favourably on the industrial and social conditions of the time.

So long as the chief supplies of gold were obtained from alluvial deposits by the simple process of washing, the winning of gold almost necessarily continued to be pursued by individuals, or by small groups of workers, who were mainly attracted by the highly speculative nature of the occupation. These workers endured the greatest hardships and ran the most serious personal risks, drawn on from day to day by the hope that some special stroke of good fortune would be theirs. This condition prevailed also in fields in which the reef gold occurred near the surface, where it was easily accessible without costly mining appliances, and where the precious metal was loosely associated with a weathered matrix. These freemilling ores could be readily handled by crushing and amalgamation with mercury, so that here also no elaborate organisation and no great expenditure of capital were necessary. A third stage was reached when the more easily worked deposits above the water-line had been worked out. Not only were more costly appliances and more elaborately organised efforts required to bring the ore to the surface, but the ore when obtained contained less of its gold in the easily recovered, and more in the refractory or combined form. The problem of recovery had now to be attacked by improved mechanical and chemical methods. The sulphides or tellurides with which the gold was associated or combined had to be reduced to a state of minute subdivision by more perfect stamping or grinding, and elaborate precautions were necessary to ensure metallic contact between the particles of gold and the solvent mercury. In many cases the amalgamation process failed to extract more than a very moderate proportion of the gold, and the quartz sand or "tailings" which still contained the remainder found its way into creeks and rivers or remained in heaps on the ground around the batteries. In neighbourhoods where fuei was available a preliminary roasting of the ore was resorted to, to oxidise or volatilise the baser metals and set free the gold; or the sulphides, tellurides, \&c., were concentrated by washing, and the concentrates were taken to smelting or chlorinating works in some favourable situation where the more elaborate metallurgical methods could be economically applied. Many efforts were also made to apply the solvent action of chlorine directly to the unconcentrated unroasted ores; but unfortunately chlorine is an excellent solvent for other substances besides gold, and in practice it was found that its solvent energy was mainly exercised on the base metals and metalloids, and on the materials of which the apparatus itself was constructed.

This to the best of my knowledge is a correct, if rather sketchy, description of the state of matters in 1889 when the use of a dilute solution of cyanide of potassium was first seriously proposed for the extraction of gold from its ores. Those of us who can recall the time will remember that the proposal was far from favourably regarded from a chemical point of view. The cost of the reagent, its extremely poisonous nature, the instability of its solutions, its slow action-such were the difficulties that naturally presented themselves to our minds. And, even granting that these difficulties might be overcome, there still remained the serious problem of how to recover the gold in metallic form from the extremely dilute solutions of the cyanide of gold and potassium. How each and all of these difficulties have been swept aside, how within little more than a decade this method of gold extraction has spread over the gold-producing countries of the world, now absorbing and now replacing the older processes, but ever carrying all before it-all this is already a twice-told tale which I should feel hardly justified in 
alluding to were it not for the fact that we are to-day meeting on the Rand where the infant process made its début nearly fourteen years ago. The Rand to-day is the richest of the world's goldfields, not only in its present capacity, but in its potentialities for the future; twenty years ago its wonderful possibilities were quite unsuspected even by experts.

It is not for me to describe in detail how the change has been accomplished; this task will, we know, be far better accomplished by representative chemists who are now actively engaged in the work. But for the chemists of the British Association it is a fact of great significance that they are here in the presence of the most truly industrial development of gold production which the world has yet seen; a development moreover that is founded on a purely chemical process which for its continuance requires, not only skilled chemists to superintend its operation, but equally skilled chemists to supply the reagent on which the industry depends.

In 1889 the world's consumption of cyanide of potassium did not exceed fifty tons per annum. This was produced by melting ferrocyanide with carbonate of potassium, the clear fused cyanide so obtained being decanted from the carbide of iron which had separated. The resulting salt was a mixture of cyanide, cyanate, and carbonate which was sometimes called cyanide of potassium for the hardly sufficient reason that it contained 30 per cent. of that salt. When the demand for gold extraction arose, it was at first entirely met by this process, the requisite ferrocyanide being obtained by the old fusion process from the nitrogen of horns, leather, \&c. In I89I the first successful process for the synthetic production of cyanide without the intervention of ferrocyanide was perfected, and the increasing demand from the gold mines was largely met by its use. At present the entire consumption of cyanide is not much short of 10,000 tons a year, of which the Transvaal goldfield consumes about one-third. Large cyanide works exist in Great Britain, Germany, France, and America, so that a steady and sure supply of the reagent has been amply provided. In 1894 the price of cyanide in the Transvaal was $2 s$. per pound; to-day it is one-third of that, or $8 d$. During the prevalence of the high prices of earlier years the manufacture was a highly speculative one, and new processes appeared and disappeared with surprising suddenness, the disappearance being generally marked by the simultaneous vanishing of large sums of money. To-day the manufacture is entirely carried out in large works scientifically organised and supervised, and, both industrially and commercially, the speculative element has been eliminated.

Chemistry has so often been called on to play the part of the humble and unrecognised handmaiden to the industrial arts that we may perhaps be pardoned if in this case we direct public attention to our Cinderella as she shines in her rightful position as the genius of industrial initiation and direction.

To this essentially chemical development of metallurgy we owe it that in a community the age of which can only be counted by decades we find ourselves surrounded hy chemists of high scientific skill and attainments who have already organised for their mutual aid and scientific enlightenment "The Johannesburg Society of Chemistry, Metallurgy, and Mining," the published proceedings of which amply testify to the atmosphere of intellectual vigour in which the work of this great industry is carried on.

It appears, then, that while gold still maintains its position of influence in the affairs of men, the nature of that influence has undergone an important change. Not only has its widespread use as the chief medium of exchange exercised far-reaching effects on the commerce of the. world, but the vastly increased demand for this purpose has in its turn altered the methods of production. These methods have become more highly organised and scientific, and gold production is now fairly established as a progressive industry in which scope is found for the best chemical and engineering skill and talent.

The experience of more highly evolved industries in the older countries has shown that the truly scientific organisation of industry includes.in its scope a full and just consideration for the social and intellectual needs of its No. I 868 , vกL. 72] workers from highest to lowest. It augurs well, therefore, for the future of the gold industry, from the humane and social points of view, that its control should be more and more under the influence of men of scientific spirit and intellectual culture who we may feel assured will not forget the best traditions of their class.

The application of science to industry requires on the part of the pioneers and organisers keen and persistent concentration on certain well-defined aims. Any wavering in these aims or any relaxation of this concentration may lead to failure or to only a qualified success. This necessary but narrow concentration may be a danger to the intellectual development of the worker, who may thereby readily fall into a groove and so may become even less efficient in his own particular work. It certainly requires some mental strength to hold fast to the well-defined practical aim while allowing to the attention occasional intervals of liberty to browse over the wide and pleasant fields of science. But I am certain that the acquirement of this double power is well worth an effort. The mental stimulus, as well as the new experiences garnered during the excursion, will sooner or later react favourably on the practical problems, while the earnest wrestling with these problems may develop powers and intuitions which will lend their own charm to the wider problems of science.

\section{Gold and Science.}

If we re-peruse the table of the elements, not now in our capacity as "plain men" but as chemists, we shall certainly not select gold as of supreme interest chemically. Its position as chief among the noble metals, its patent of nobility, is based on its aloofness from common associations or attachments. Unlike the element nitrogen, it is mainly for itself and little if at all for its compounds, that gold is interesting. In it we can at our leisure study the metal rather than the element. Its colour and transparence, its softness and its hardness, the density as well as the extreme tenuity of some of its forms-such were the qualities which recommended it to Faraday when he desired to study the action of material particles on light. I should like to repeat to you in his own words the reasons he gave for this choice: "Because of its comparative opacity among bodies, and yet possession of a real transparency; because of its development of colour both in the reflected and transmitted rays; because of the state of tenuity and division which it permitted with the preservation of its integrity as a metallic body; because of its supposed simplicity of character; and because known phenomena appeared to indicate that a mere variation in the size of its particles gave rise to a variety of resultant colours. Besides the waves of light are so large compared to the dimensions of the particles of gold which in various conditions can be subjected to a ray, that it seemed probable that the particles might come into effective relations to the much smaller vibrations of the other particles."

I may remind you that Faraday came to the conclusion that the variety in the colours presented by gold under various conditions is due to the size of its particles and their state of aggregation. Ruby glass or ruby solutions he proved are not true solutions, nor are they molecular diffusions of gold, but they contain the metal in aggregates sufficiently large to give a sensible reflection under an incident beam of light. Through the kindness of Sir Henry Roscoe I am able to exhibit to you some of the original ruby gold preparations obtained during this research, which were afterwards presented to him by Faraday at the Royal Institution some years before his death.

By means of refined and ingenious optical methods Zsigmondy and Siedentopf have succeeded in making these ultra-microscopic particles visible in the microscope as diffraction discs; they have, further, counted the number of particles per unit area, and have from the intensity of their reflection calculated their size. In ruby glass the size of the particles in different specimens was found to vary from 4 to $79 \mathrm{I}$ millionths of a millimetre. No relation was found to hold between the colour of the particles and their absolute size. This conclusion is in direct contradiction of Faraday's belief already referred to. $\mathrm{Mr}$. J. Maxwell Garnett has recently shown that the colour 
of metallic glasses and films is determined, not only by the absolute size of the metal particles, but also by the proportion of the total volume they occupy in the medium in which they are diffused. The results of Mr. Garnett's calculations are in close agreement with a number of the observations on the colour and microstructure of thin metal films which I had already recorded, and they appear to me to supply the explanation of much that had appeared puzzling before. My own observations lead me to think that the actual microscopic particles which are to be seen, and the larger of which can also be measured, in films and solutions or suspensions, do not in any way represent the ultimate units of structure which are required by Mr. Garnett's theory, but that these particles are aggregates of smaller units built up in more or less open formation.

That a relatively opaque substance like gold may be so attenuated that when disseminated in open formation it becomes transparent is contrary to all our associations with the same operation when performed on transparent substances like glass or crystalline salts. The familiar experiment of crushing a transparent crystal into a perfectly opaque powder would not prepare us for the effect of minute subdivision on the transparence of metals. At first it might be supposed that this difference is due to the very rough and incomplete subdivision of the crystal by crushing; but this is not the case, for the perfectly transparent oxide of magnesium may be obtained in a state of attenuation comparable with that of the gold, by allowing the smoke from burning magnesium to deposit on a glass plate. The film of oxide obtained in this way is found to be built up of particles quite as minute as those of which the gold films are composed, yet the opacity of the oxide film is relatively much greater. The minute particles of the dielectric, magnesium oxide, scatter and dissipate the light waves by repeated reflection and refraction, while the similar particles of the metallic conductor, gold, act as electrical resonators which pass on some of the light waves while reflecting others. Specimens of films of gold and silver and of magnesium oxide are exhibited on the table and on the lantern screen. When the metallic particles are in this state of open formation and relative transparence, it was found that the electrical conductivity of the films had completely disappeared. Films of this description were found to have a resistance of more than 1,000,00o megohms as compared with only six ohms in the metallic reflecting condition.

\section{Molecules in the Solid State.}

My examination of gold films and surfaces has revealed the fact that during polishing the disturbed surface film behaves exactly like a liquid under the influence of surface tension. At temperatures far below the melting point molecular movement takes place under mechanical disturbance, and the molecules tend to heap up in minute mounds or flattened droplets. These minute mounds are often so shallow that they can only be detected when the surface is illuminated by an intense, obliquely incident beam of light. I have estimated that these minute mounds or spicules can be seen in this way in films which are not more than five to ten micro-millimetres in thickness. A film of this attenuation may contain so few as ten to twenty molecules in its thickness.

When moderately thin films of gold are supported on glass and heated at a temperature of $400^{\circ}-500^{\circ}$, they become translucent, and the forms assumed under the influence of surface tension can be readily seen by transmitted light. It was in this way that the beautiful but puzzling spicular appearance by obliquely reflected light was first explained as due to the granulation of the surface under the influence of surface tension. Photomicrographs of these films are exhibited.

Turning now to the mechanical properties of metals, we find that gold has proved itself of great value in the investigation of some of these. It has long been recognised as the most malleable and ductile of the metals, whilst its chemical indifference tends to preserve it in a state of metallic purity throughout any prolonged series of operations.

The artificers in gold must very early have learned that its malleability and ductility are not qualities which indefinitely survive the operations of hammering and wiredrawing. A piece of soft gold beaten into a thin plate NO. I 868 , VOL. 72$]$ does not remain equally soft throughout the process, but spreads with increasing dificulty under the hammer. If carelessly beaten it may even develop cracks round its edges. We may assume that the artificers in gold very soon discovered that by heating, the hardened metal might be restored to its former condition of softness.

In connection with the study of the micro-metallurgy of iron and steel during recent years it has been recognised that heat annealing is, as a rule, associated with the growth and development of crystalline grains, and Prof. Ewing and $\mathrm{Mr}$. Rosenhain have shown that overstrain is often if not invariably associated with the deformation of these crystalline grains by slips occurring along one or more cleavage planes. This hypothesis, though well supported up to a point by microscopic observations on a variety of metals, offers no explanation of the natural arrest of malleability or ductility which occurs when the overstrain has reached a point at which the crystalline grains are still, to all appearance, only slightly deformed. At this stage there is no obvious reason why the slipping of the crystalline lamellæ should not continue under the stresses which have initiated it. But far from this being the case, a relatively great increase of stress produces little or no further yielding until the breaking point is reached and rupture takes place.

The study of the surface effects of polishing, already referred to, had shown that the thin surface film retained no trace of crystalline structure; while it also gave the clearest indications that the metal had passed through a liquid condition before settling into the forms prescribed by surface tension. From this it was argued that the conditions which prevail at the outer surface might equally prevail at all inner surfaces where movement had occurred, so that every slip of one crystalline lamella over another would cause a thin film of the metal to pass through the liquid phase to a new and non-crystalline condition. By observations on the effects of beating pure gold foil, it was found that the metal reached its hardest and least plastic condition only when all outward traces of crystalline structure had disappeared. It was also ascertained that this complete destruction of the crystalline lamellæ and units could only be accomplished in the layers near the surface, for the hardened substance produced by the flowing under the hammer appears to encase and protect the crystalline units after they become broken down to a certain size. By carefully etching the surface in stages by means of chlorine water or cold aqua regia, the successive layers below the surface were disclosed. The surface itself was vitreous; beneath this was a layer of minute granules, and lower still the distorted and brokenup remains of crystalline lamellæ and grains were embedded in a vitreous and granular matrix. The vitreouslooking surface layer represents the final stage in the passage from soft to hard, from crystalline to amorphous. By heating the beaten foil, its softness was restored; and on etching the annealed metal it was found that the crystalline structure also was fully restored. Photomicrographs showing these appearances are exhibited. These microscopic observations were fully confirmed by finding well-marked thermo-electrical and electro-chemical distinctions between the two forms of metal, the hard and soft or the amorphous and the crystalline. The determination of a definite transition temperature at which the amorphous metal passes into the crystalline metal further confirms the phase view of hardening by overstrain and softening by annealing.

It was subsequently proved that the property of passing from crystalline to amorphous by mechanical flow, and from amorphous to crystalline by heat at a definite transition temperature, is a general one which is possessed by all crystalline solids which do not decompose at or below their transition temperature. The significance of this fact I venture to think entitles it to more than a passing reference. It appears to me to mean that the transition from amorphous to crystalline is entitled to take its place with the other great changes of state, solid to liquid, liquid to gas, for like these it marks a change in the molecular activity which occurs when a certain temperature is reached. It is entitled to take this place because there is every indication that the change is as general in its nature as the other changes of state. Compare it for instance, with the allotropic changes with which chemists have been 
familiar. These are for the most part changes which are special to particular elements or compounds, and are usually classed with the chemical properties by which the substances may be distinguished from each other. Very different is the amorphous crystalline change, for although in particular cases it may have been observed and associated with allotropic changes, yet the causes of its occurrence are more deeply founded in the relations between the molecules and the heat energy by which their manifold properties are successively unfolded as temperature is raised from the absolute zero. At this transition point we find ourselves face to face with the first stirrings of a specific directive force by which the blind cohesion of the molecules is ordered and directed to the building up of the most perfect geometric forms. It is hardly possible any longer to regard the stability of a crystal as static and inert, and independent of temperature; rather must its structure and symmetry be taken as the outward manifestation of a dynamic equilibrium between the primitive cohesion and the kinetic energy imparted by heat. Even before the discovery of a definite temperature of transition from the amorphous to the crystalline phase we had in our hands the proofs that in certain cases the crystalline state can be a state of dynamic, rather than of static equilibrium. The transition of sulphur from the rhombic to the prismatic form supplies an example of crystalline stability which persists only between certain narrow limits of temperature. Within these limits the crystal is a "living crystal" if one may borrow an analogy from the organic world. It can still grow, and it will under proper conditions repair any damage it may receive.

The passage of the same substance through several crystalline phases, each only stable over a limited range of temperature, strongly supports the general conclusion drawn from the existence of a stability temperature between the amorphous and crystalline phases, namely, that the crystalline arrangement of the molecules requires for its active existence the particular kind or rate of vibration corresponding with a certain range of temperature. Below this point the crystal may become to all appearance a mere pseudomorph. with no powers of active growth or repair. But these powers are not extinct--they are only in abeyance ready to be called forth under the energising influence of heat. This temporary abeyance of the more active properties of matter is strikingly illustrated by the early observations of Sir James Dewar at the boiling point of liquid air, and more recently at that of liquid hydrogen. At the latter temperature even chemical affinity becomes latent. In metals it was found that the changes in their physical properties brought about by these low temperatures are not permanent, but only persist so long as the low temperature is maintained. During the past year $\mathrm{Mr}$. R. A. Hadfield has supplemented these earlier results by making a very complete series of observations on the effect of cooling on the mechanical properties of iron and its alloys. The tenacity and hardness of the pure metal and its alloys at the ordinary temperature and at $-182^{\circ}$ have been compared, and it has been found that these qualities are invariably enhanced at the lower temperature, but that they return exactly to their former value at the ordinary temperature. By the mere abstraction of heat between the temperatures of $18^{\circ}$ and $-182^{\circ}$ the tensile strength of pure metals is raised 50 to 100 per cent. In pure iron the increase is from 23 tons per square inch at $18^{\circ} \mathrm{C}$. to $5^{2}$ tons at $-182^{\circ}$; in gold from 15.1 tons to 22.4 tons; and in copper from 19.5 tons to 26.4 . This increase is not, I think, due to the closer approximation of the molecules, for the coefficient of expansion of most metals below $0^{\circ}$ is extremely small. Neither is it due to permanent changes of molecular arrangement or aggregation, for Mr. Hadfield has obtained a perfectly smooth and regular cooling curve for iron between $18^{\circ}$ and $-182^{\circ}$, and there appears to be no indication of the existence of any critical point between these temperatures. Further, the complete restoration of the original tenacity on the return to the higher temperature shows that no permanent or irreversible change has occurred during cooling. Everything therefore indicates that the increase of tenacity which occurs degree by degree as heat is removed is due to the reduction of the repulsive force of molecular vibration, so that the primary cohesive force can assert itself more and more completely as the absolute zero is approached.

The metals experimented with by Mir. Hadfield were all in the annealed or crystalline condition, so that the molecules must have exerted their mutual attractions along the directed axes proper to this state. It is to be expected that similar experiments with the metals in the amorphous state may throw light on the question whether and to what extent the crystalline state depends on a dynamic equilibrium between the forces of cohesion and repulsion, or whether a directed cohesion exists fully developed in the molecules at the absolute zero. ${ }^{1}$

The phenomena of the solid state throw an interesting light on the interplay of the two great forces, the primative or blind cohesion which holds undisputed sway at the absolute zero, and the repulsion due to the molecular vibrations which is developed by heat. This interplay we know continues through the states which succeed each other as the temperature is raised, until a point is reached at which the molecular repulsions so far outweigh the cohesive force that the substance behaves like a perfect gas. The problems of molecular constitution are more likely to be elucidated by a study of the successive states between the absolute zero and the vaporising temperature than at the upper ranges where the gaseous state alone prevails. The simplicity of the laws which govern the physical behaviour of a perfect gas is very attractive, but we must not forget that this simplicity is only possible because repulsion has so nearly overcome cohesion that the latter may be practically ignored. The attractiveness of this simplicity should not blind us to the fact that it is in the middle region, where the opposing forces are more nearly equal, that the most interesting and illuminating phenomena are likely to abound. The application of the gas laws to the phenomena of solution and osmosis appears to be one of those cases in which an attractive appearance of simplicity in the apparent relations may prove very misleading.

Before passing from the specially metallic qualities of gold I will only remind you of the important part it has played in the researches on the diffusion of metals by the late Sir William Roberts-Austen, and in those of $\mathrm{Mr}$. Haycock and Mr. Neville on the freezing points of solutions of gold in tin, which led to the recognition of the monatomic nature of the molecules of metals.

\section{Molecules in Solution.}

It has occurred to me that the practice of the cyanide process of gold extraction presents us with several new and interesting aspects of the problems of solution. As you are aware, the gold is first obtained from the ore in the form of a very dilute solution of cyanide of gold and potassium from which the metal has to be separated, either by passing it through boxes filled with zinc shavings, or by electrolysis in large cells.

The solution as it leaves the cyanide-vats may contain gold equal to 100 grains or more per ton, and as it leaves the precipitating-boxes it may contain as little as I or 2 grains and as much as 20 grains. In the treatment of slimes much larger volumes of solution have to be dealt with, and in this case solutions containing 18 grains per ton have been regularly passed through the precipitatingboxes, their gold content being reduced to $I^{\frac{1}{2}}$ grains per ton. In round numbers we may say that I gram of gold is recovered from I cubic metre of solution, while o.I gram is left in the solution. Even from the point of view of the physical chemist we are here in presence of solutions of a very remarkable order of dilution. A solution containing I gram per cubic metre is in round numbers $\mathrm{N} / 200,000$, and the weaker solution containing $0 \cdot x$ gram is $\mathrm{N} / 2,000,000$. It is convenient to remember that the latter contains a little more than $\mathrm{I} \frac{1}{2}$ grains per ton. In experiments on the properties of dilute solutions the extreme point of dilution was reached by Kohlrausch, who employed solutions containing $\mathrm{I} / \mathrm{I00}, 000$ of a gram-molecule of solute per litre for his conductivity experiments. These solutions were therefore twice as strong as the gold solution with I gram per cubic metre, and twenty times as strong as the

1 Since the above was written a series of observations has been made on the influence of low temperature on the tenacity of pure metals in the amorphous condition. These observations will form the subject of a separat communication to the Section. 
more dilute solution. This fact must be my excuse for placing before you the results of a few simple calculations as to the molecular distribution in these solutions, which have certainly given me an entirely new view of what constitutes a really dilute solution from the molecular point of view.

In estimating the number of molecules in a given volume of solution the method adopted is to divide the space into minute cubical cells, each of which can exactly contain a sphere of the diameter of the molecule. In this way a form of piling for the molecules is assumed which, though not the closest possible, may quite probably represent the piling of water molecules. Taking the molecular diameter as $0.2 \times 10^{-6}$ millimetres - a figure which is possibly too small for the water molecules and too large for the gold -it is found that a cubic millimetre of solution contains $125 \times 10^{18}$ molecules, or 125 quadrillions. The head of an ordinary pin, if it were spherical, would have a volume of about I cubic millimetre.

If these water molecules could be arranged in a single row, each molecule just touching its two nearest neighbours, the length of the row would be $25,000,000$ kilometres. A thread of these fairy beads, which contained the molecules of one very small drop of a volume of 6 cubic millimetres, would reach from the earth to the sun, a distance of about $150,000,000$ kilometres.

In a solution containing $\mathrm{I}^{\frac{1}{2}}$ grains of gold per ton, or 1 decigram per cubic metre, the ratio of gold molecules to water molecules is as I : 193,000,000. Each cubic millimetre of the solution, therefore, contains $6,500,000,000$ gold molecules. If these are uniformly distributed throughout the solution each will be about 400 micro-millimetres, or I $/ 60,000$ of an inch, from its nearest neighbours. This is not really very wide spacing, for the point of the finest sewing-needle would cover about 1,500 gold molecules.

If a cubic metre of solution could be spread out in a sheet one molecule in thickness it would cover an area of $r, 680$ square miles, and nowhere in this area would it be possible to put down the point of the needle without touching some hundreds of gold molecules simultaneously.

According to Prof. Liversidge, sea-water contains on the average about I grain of gold per ton. If this is the case, then the above figures for the dilute cyanide solution apply with only a slight modification to sea-water. No drop, however small it may be, can be removed from the ocean which will not contain many millions of gold molecules, and no point of its surface can be touched which is not thickly strewn with these. From this molecular point of view we must realise that our ships literally float on a gilded ocean!

From time to time adventurers arise who attempt to launch upon this gilded ocean unseaworthy ships freighted with the savings of the trusting investor. In order that nothing which has been said here may tempt anyone to contribute to the freighting of these ships, let me hasten to point out that the weakest of the cyanide solutions here referred to is richer in gold than sea-water is reported to be. The practical conclusion from this comparison is sufficiently obvious. If the cyaniding expert, whose business it is to extract gold from dilute solutions, finds that it does not pay to carry this extraction beyond a concentration of 2 or 3 grains per ton, even when the solution is already in his hand, and when, therefore, the costs of treatment are at their minimum, how can it possibly pay to begin the work of extraction on sea-water, a solution of one-half the richness, which would have to be impounded and treated by methods which could not fail to be more costly in labour and materials than the simple process of zinc-box precipitation? It is generally unsafe to prophesy, but in this case I am rash enough to risk the prediction that if ever the gold mines of the Transvaal are shut up it will not be owing to the competition of the gold resources of the ocean.

In these calculations with reference to the dilute cyanide solutions it is assumed that the gold molecules are uniformly distributed, that they are practically equidistant from each other. There appears to me to be considerable doubt whether we have any right to make this assumption. Leaving out of account for the moment the action of the water molecules, it would appear that as long as the gold molecules are so numerous that a uniform distribution would bring them within the range of each other's attraction, we can imagine that all submerged molecules would be in equilibrium so far as the attractions of their own kind are concerned, being subjected to a uniform pull in all directions. This condition would certainly make for uniform distribution. But when the distance between them exceeds the range of the molecular forces, it is evident that an entirely new condition is introduced, and it seems not improbable that the widely distributed molecules would tend to drift into clouds in which they are brought back within the range of these forces. The range of the cohesive forces in water and aqueous liquids. is usually taken from 50 to 100 micro-millimetres, and I am disposed to think that ten times this amount would not be an excessive estimate of the range in the case of gold. If the range for gold be taken as 500 micro-millimetres, then the gold molecules of the dilute gold solution, which are spaced at 400 micro-millimetres apart, are just within the range of each other's attraction, and their distribution is, therefore, likely to be uniform. Sut by a further dilution to half concentration, the equilibrium would be liable to be disturbed, and denser clouds of gold molecules would be formed, with less dense intervals between them.

In preparing the zinc boxes through which the gold solution is passed, very great care has to be exercised to ensure that the contact surface of the zinc is used to the best advantage. With this object the packing of the zinc shavings is so managed that the solution is spread ovẹr the zinc surface in as thin sheets as possible. The object, of course, is to bring as many of the gold molecules as possible into actual contact with the zinc. The gold molecules found in the solution leaving the boxes are those which have not been in contact with the zinc. Yet we have seen that these molecules are still so numerous that they are within $1 / 60,000$ of an inch of each other. If these molecules are in a state analogous to the gaseous state, with diffusive energy of the same order as that of the gas molecule, it is difficult to imagine how they can escape without coming in contact with the zinc surface during their tortuous passage through the boxes and being deposited there. Yet they do escape, even when the velocity of the solution in passing over the zinc surfaces is so slow as $10 \mathrm{~cm}$. per minute or $\mathrm{I} \cdot 6 \mathrm{~mm}$. per second.

We may regard the condition of these isolated gold molecules, or the more complex auricyanide of potassium molecules, as typical of that of the solute molecules in a dilute solution of any non-volatile solid. They are solid molecules sparsely distributed among a multitude of intensely active solvent molecules, the temperature of the solution being many hundred degrees below that at which they could of themselves assume the greater freedom of the liquid or gaseous state. These solute molecules have to a great extent been set free from the constraining effect of their cohesive forces, but it is important to remomber that this freedom has not been attained by the increase of their own kinetic energy as in liquefaction by heat. Their freedom and the extra kinetic energy they have acquired have in some way been imparted to them by the more active solvent molecules; for, if the solvent could be suddenly removed, leaving the solute molecules still similarly distributed in a vacuous space, they would eventually condense into a solid aggregate. This must be the case, for the non-volatile solute has no measurable vapour pressure at the temperature of the solution. The kinetic energy of the solute molecules is of itself quite insufficient to endow them with the properties of the gaseous or even of the liquid molecule, even when their cohesive forces have been weakened or overcome by separation.

If the energy employed in this separation is not intrinsic to the solute molecule then it must in some way have been imparted by the solvent molecules. It therefore becomes important to compare the energy endowment of one set of molecules with that of the other.

Compared with other solids, ice at its freezing point has very little hardness or tenacity: the cohesion of its molecules has been much relaxed by the great absorption of heat energy between the absolute zero and the freezing point. If an average specific heat of 0.5 over the whole range be assumed, the heat absorption of one gram amounts to 136.5 calories. In the transition to the liquid state at $0^{\circ}$ a further absorption of 79 calories takes place, so that 
a gram of liquid water at the freezing point contains the heat energy of 215.5 calories. The fact that water has the high vapour pressure of $4.6 \mathrm{~mm}$. of mercury at the freezing point is probably a result of this enormous store of energy. As a liquid, therefore, it is natural to expect that its molecules will exhibit effects proportionate to this great store of energy. This expectation appears to be realised when we consider not only its properties as the universal solvent, but its osmotic and diffusive energy in solutions in which it is the solvent.

To complete the comparison it is only necessary to calculate the heat energy of gold at $0^{\circ}$. Taking its specific heat as 0.032 , a gram of gold at $0^{\circ}$ contains 8.7 calories. A gram-molecule, therefore, contains in round numbers I700 calories as compared with 3880 calories in a grammolecule of water.

Taking into consideration not only this greater store of energy, but also the much smaller cohesive force of water as compared with the majority of solid solutes, there can be no doubt that the active rôle in aqueous solutions of this type must be assigned to the solvent, not to the solute molecules.

This leads to the important conclusion that the energy of solution, of diffusion, and of osmosis is due, not to the imaginary gaseous energy of the solute, but to the actual liquid energy of the solvent molecules. When this conclusion is reached a new physical explanation of these phenomena is in our hands, and we are relieved from the strain to the imagination involved in the application of the gas theory to solutions of non-volatile solids.

This transference of the active rôle to the solvent molecules does not in any way affect the well-established conclusions based on the laws of thermodynamics as to the energy relations in these phenomena, for it has always been recognised that these conclusions have reference to the average conditions prevailing in large collections of relatively minute units. Wherever the gas analogy has appeared to hold it has not necessarily involved more than this, that the observed effects are in proportion to the number of these minute units in a given volume.

In applying the gas theory to the physical explanation of osmotic pressure it has been the custom to regard this pressure as directly due to the bombardment of the semipermeable membrance by the solute molecules. But this conception completely ignores the fact that the pressure developed is a hydrostatic, not a gaseous pressure, and that the hydrostatic pressure results directly from the penetration of the solvent molecules from the other side of the partition.

It appears to me-more natural to abandon the gas analogy altogether, to regard the molecules as in the solid and liquid condition proper to their temperature, and to apportion to them their respective parts in the active changes according to their obvious endowment of energy.

Applying this view to the case of a solution and a solvent separated by a semi-permeable membrane, it is seen that the pressure rises on the solution side, because the pure solvent molecules on the other side have some advantage for the display of their energy over the similar molecules in the solution. This effect in its most general form may be attributed to the dilution of the solvent by the solute molecules. In cases where the osmotic pressure appears to obey Boyle's law the effect is exactly measured by the number of solute molecules per unit volume. But the facts of this position are in no way changed if the effect is taken to be due to the activity of an equal number of solvent molecules, for we then see that each solute molecule by cancelling the activity of one solvent molecule on the solution side permits a solvent molecule from the other side to enter the solution.

What the exact mechanism of this cancellation is there is at present no evidence to show, and the caution originally given by Lord Kelvin with reference to the undue forcing of the gas analogy must also be applied to the suggestion now put forward. But as a means of making the suggestion a little more clear I give here a simple diagram on which $\mathrm{A}$ represents a single perforation in a semi-permeable membrane, $P$, on both sides of which there is only pure solvent. For the sake of clearness the molecules are shown only as a single row. Normally there will be no passage of solvent molecules from side to side, for No. I 868, vOL. 72$]$ the average kinetic energy of the rnolecules on both sides is equal. This state of equilibrium is indicated on the diagram by marking with a cross the molecule which is exactly halfway through the partition.

At $\mathrm{B}$ a single solute molecule, $\mathrm{s}$, has been introduced at the right side. If this molecule exactly cancels the energy of one solute molecule at its own end of the row, the equilibrium point will move one molecule to the right, the solvent molecules will move in the same direction, and one of their number will enter on the solution side. So long as the row includes one, and only one, solute molecule, the equilibrium will remain unchanged and no more solute molecules will pass in. If another solute molecule arrives
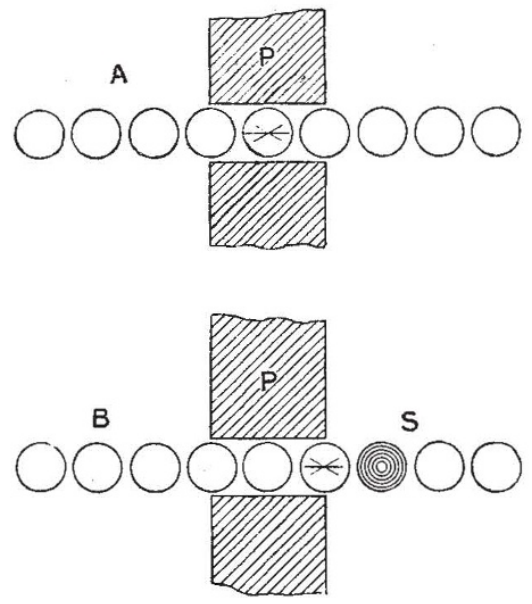

on the scene, the equilibrium will again be disturbed in the same way as before, and another solvent molecule will pass into the solution.

This mechanism accomplishes to some extent the work of a "Maxwell. Demon," in so far at least as it takes advantage of the movement of individual molecules to raise one part of a system at a uniform temperature to a higher level of energy.

\section{A Mechanical View of Dissociation in Dilute Solutions.}

The view that the phenomena of solution depend on the relative kinetic energy of the solvent and solute molecules appears to apply with special force to the phenomena of dissociation in dilute solutions. Under the gas theory there does not appear to be any reason why the solute molecules should dissociate into their ions. So obvious is this absence of any physical motive that Prof. Armstrong has happily referred to the dissociation as "the suicide of the molecules." Others have proposed to ascribe the phenomenon to what might be called "the fickleness of the ions," thus supposing that the ions have an inherent love of changing partners. These may be picturesque ways of labelling certain views of the situation, but the views themselves do not appear to supply any clue to the physical nature of the phenomena. With the acceptance of the view that the phenomena of solution are largely due to the kinetic energy of the solvent molecules, the phenomena of dissociation also appear to take their place as a natural result of this activity. For consider the situation of an isolated molecule of cyanide of gold and potassium closely surrounded by and at the mercy of some millions of water molecules all in a state of intense activity. The rude mechanical jostling to which the complex molecule is subjected will naturally tend to break it up into simpler portions which are mectanically more stable. The mechanical analogy of a ball mill in which the balls are selfdriven at an enormous velocity is probably rather crude, but it may at least help us to picture what, on the view now advanced, must be essentially a mechanical operation.

In importing this mechanical view of the breaking down of complex into simpler molecules we are not without some solid basis of facts to go upon. My own observations have shown that even in the solid state the crystalline molecule can be broken down by purely mechanical means 
into the simpler units of the amorphous state; and, further, that the water molecules of a crystal may by the same agency be broken away from their combination with the salt molecules. Since the publication of the earlier of these observations Prof. Spring has shown that the acid sulphates of the alkali metals may be mechanically decomposed into two portions, one of which contains more acid, and the other more base than the original salt. It is important to recognise that in these three apparently short steps the transition has been made from the overcoming of the simple cohesion of similar molecules in contact with each other to the breaking asunder of the chemical union of dissimilar molecules. At each step the solid molecules appear, not as mere ethereal abstractions, but as substantial portions of matter which can be touched and handled mechanically.

The physical properties of a gas are primarily due to its being an assemblage of rapidly moving molecules. These simpler and more general properties can coexist with, and may be modified by, the more complex relations introduced by chemical affinity as it occurs in compound gases and mixtures.

It appears to me quite legitimate similarly to regard the physical properties of a liquid as due to its being an assemblage of rapidly moving molecules. The liquid system is highly condensed, and the motions of its molecules are controlled by the cohesive as well as by the repulsive forces. The closer approximation of the molecules may reduce their mean free path to an extremely small amount, or it may even cause their translatory motion to disappear, so that the whole kinetic energy of the liquid molecules may be in the form of rotation or vibration.

As we can imagine a perfect gas, so also may we imagine a perfect liquid, the physical properties of which are as simply related to the laws of dynamics as are those of the gas. But the conditions of the liquid state being also those most favourable to the play of chemical affinity, the internal equilibrium of solutions or of mixed liquids must be a resultant of this affinity together with the primary forces of the ideal liquid state.

An ideally perfect solution-that is, a solution the physical properties of which are determined solely by the number of molecules it contains in a given volume-must consist of a solvent and a solute which have no chemical affinity for each other, so that their molecules will neither associate nor dissociate in solution. Probably only comparatively few solutions will be found which even approximate to this ideal perfection. But it appears to me that the study of the problems of the liquid and the dissolved states may be much simplified by the recognition (1) that the primary physical properties of liquids and solutions are due to the fact that they are assemblages of molecules endowed with the amount and the kind of kinetic energy which is proper to their temperature; and (2) that as these primary physical properties of the liquid and dissolved states may be masked and interfered with by chemical affinity, they should be studied as far as possible in examples where the influence of this force is either absent or at a minimum.

\section{NOTES.}

WE regret to learn of the death, at the age of seventyeight, of Dr. T. R. Thalén, professor of physics at the University of Upsala, and one of the most eminent Swedish men of science. The Rumford medal was awarded to him by the Royal Society for his researches on spectrum analysis, and a gold medal was awarded to him by the Swedish Association of Ironmasters in 1874 for his investigations of magnetic iron ore deposits.

A Reuter telegram from Berlin states that the International Conference for the Investigation of Earthquakes met on Tuesday at the Ministry of the Interior, under the presidency of Privy Councillor Dr. Lewald. All the States which possess organised staffs for the investigation of earthquakes were invited by the German Government NO. 1868 , vol. 72$]$ to take part in the conference. The conference is expected to last two days.

THE Government Eclipse Expedition in charge of Sir Norman Lockyer, K.C.B., has arrived at Palma, Balearic Islands, where the instruments will be erected for observations of the total solar eclipse on August 30. A Reuter telegram from Madrid reports that the telegraph authorities have decided to frank all telegrams dispatched by members of the various astronomical expeditions regarding observations of the eclipse.

THE London County Council has erected a memorial tablet on No. I4 Hertford Street, Park Lane, where Edward Jenner, the originator of vaccination, resided in 1803 ; and also on No. 34 Gloucester Square, Hyde Park, where Robert Stephenson, the engineer, resided at one time.

THE death is announced of the Rev. Dr. J. Keith. He was one of the leading educationists of the north of Scotland, and took an active interest in scientific pursuits, especially botany.

THE Times correspondent at Wellington, N.Z., states that the Postmaster-General hopes, with the cooperation of Australia, to have wireless telegraphv established across the Tasman Sea within twelve months. The cost will be $28,000 l$.

THE meeting of the tenth International Navigation Congress will be held at Milan from September 24-30. Particulars can be obtained from the secretary, M. Dufourny, 38 Rue de Louvain, Brussels, or from M. Saujast Di Teulada, Villa Real, Milan.

MR. W. E. LANGDON, formerly telegraph superintendent and chief of the electrical department of the Midland Railway, died on Saturday last, August 12. He was for many years a member of the Institution of Electrical Engineers, and was president for the session of $190 \mathrm{I}-2$.

Profs. Rubert Boyce and Ronald Ross, of the Liverpool School of Tropical Medicine, left Liverpool on Saturday by the Campania for New York. They are proceeding to New Orleans, their services having been offered to the authorities in connection with the outbreak of yellow fever at that port.

A Reuter message from Hong Kong, dated August I2, reports that for nine hours a continuous series of earthquake shocks, two of them prolonged, have been felt at Macao. Slight shocks have been experienced in Hong Kong. An earthquake shock was felt at Chamonix on August 13, at $10.30 \mathrm{a} . \mathrm{m}$. The usual subterranean rumbling noise was heard.

Mr. Gerald Dudgeon has bcen appointed by the Secretary of State for the Colonies to examine and report upon questions relating to the development of the agricultural resources (including cotton) of British West Africa. His title is Superintendent of Agriculture for the British West African Colonies and Protectorates.

THE weather report issued by the Meteorological Office for the week ending August i2 shows that in all the eleven districts into which the British Islands are divided the rainfall since the beginning of the year is below the average, except in the north of Scotland, where the excess is 5.2 inches. The deficiency amounts to 4.6 inches in the north-east of England, and to 3.0 inches in the Midland counties. While at the end of the week in question nearly the whole of England and Ireland were under the influence 